\title{
Schizophrenia and drug addiction comorbidity: recent advances in our understanding of behavioural susceptibility and neural mechanisms
}

\author{
Victoria Menne ${ }^{1,2}$ and Rose Chesworth ${ }^{2, *}$ \\ ${ }^{1}$ Faculty of Psychology and Neuroscience, Maastricht University, Maastricht, The Netherlands and ${ }^{2}$ School \\ of Medicine, Western Sydney University, Campbelltown, NSW, Australia \\ *r.chesworth@westernsydney.edu.au
}

\begin{abstract}
Schizophrenia is a severe psychiatric disorder which is worsened substantially by substance abuse/addiction. Substance abuse affects nearly $50 \%$ of individuals with schizophrenia, extends across several drug classes (e.g. nicotine, cannabinoids, ethanol, psychostimulants) and worsens overall functioning of patients. Prominent theories explaining schizophrenia and addiction comorbidity include the primary addiction hypothesis (i.e. schizophrenia susceptibility primes drug reward circuits, increasing drug addiction risk following drug exposure), the two-hit hypothesis (i.e. drug abuse and other genetic and/or environmental risk factors contribute to schizophrenia development) and the self-medication hypothesis (i.e. drug use alleviates schizophrenia symptoms). Animal models can be used to evaluate the utility and validity of these theories. Since this literature was last reviewed by Ng and colleagues in 2013 [Neurosci Biobehav Rev, 37(5)], significant advances have been made to our understanding of schizophrenia and substance abuse comorbidity. Here we review advances in the field since 2013, focussing on two key questions: 1) Does schizophrenia susceptibility increase susceptibility to drug addiction (assessing the primary addiction hypothesis), and 2) Do abused drugs exacerbate or ameliorate schizophrenia symptoms (assessing the two-hit hypothesis and the self-medication hypothesis). We addressed these questions using data from several schizophrenia preclinical models (e.g. genetic, lesion, neurodevelopmental, pharmacological) across drug classes (e.g. nicotine, cannabinoids, ethanol, psychostimulants). We conclude that addiction-like behaviour is present in several preclinical schizophrenia models, and drugs of abuse can exacerbate but also ameliorate schizophrenia-relevant behaviours. These behavioural changes are associated with altered receptor system function (e.g. dopaminergic, glutamatergic, GABAergic) critically implicated in schizophrenia and addiction pathology.
\end{abstract}

Key words: Schizophrenia; Drug Addiction; Drug Abuse; Rodent Model; Behaviour; Molecular

\section{Introduction}

Schizophrenia is a severe psychiatric illness affecting approximately $1 \%$ of the population worldwide [1], and is characterised by a combination of positive symptoms (e.g. delusions, hallucinations, conceptual disorganisation), negative symptoms (e.g. apathy, social withdrawal, emotional blunting) and cognitive impairment (e.g. impaired executive function, working memory and attention) [2]. Sex differences are evident in schizophrenia: males have a higher incidence rate and an earlier onset of schizophrenia (although females show an increased incidence of schizophrenia following menopause), males present with worse negative symptoms and do not re- spond as well to antipsychotic treatment as females; several of these differences have been attributed to protective effects of estrogen in females [3].

Drug abuse and addiction (used interchangeably) is very common in patients with schizophrenia, occurring up to five times more frequently than in the general population, and affecting nearly $50 \%$ of patients (excluding nicotine dependence, which affects nearly $90 \%$ of patients with schizophrenia) $[4,5]$. For example, cannabis abuse occurs in $50 \%$ of patients with schizophrenia, compared to $1 \%$ of the general population, nicotine abuse occurs in $29 \%$ of patients, compared to $13 \%$ of the general population, and alcohol abuse occurs in $43-65 \%$ of patients, compared to $5 \%$ of the general population [5]. 
Drug abuse causes significant problems for patients by worsening symptoms, limiting treatment compliance, increasing psychotic relapse and hospitalisation, and increasing suicide risk [6-11]. Some drugs, such as cannabis and methamphetamine, increase risk for developing psychosis and schizophrenia; however, chronic drug abuse can also develop after disease onset, indicating a complex bidirectional relationship [12]. Several drug classes are abused in schizophrenia, including cannabis, psychostimulants (e.g. methamphetamine, cocaine), alcohol and nicotine [5]. To the authors' knowledge, sex differences in the prevalence of substance abuse in patients with schizophrenia has not been reported. Despite high rates of substance abuse in schizophrenia and the significant problems it causes, the causes of comorbidity are unclear.

\subsection{Theories of schizophrenia and drug abuse comor- bidity}

Several theories have been developed to help explain the high rate of substance abuse in schizophrenia (see [13]). The selfmedication theory suggests that individuals with schizophrenia abuse substances to ameliorate symptoms of the disease [14]; however, this has received limited empirical support (e.g. $[15,16])$. The primary addiction hypothesis purports that schizophrenia and drug addiction share similar pathophysiology in mesocortolimbic circuitry, and thus individuals predisposed to schizophrenia also have an elevated propensity for addiction [17]. In the primary addiction hypothesis, drug addiction can occur prior to, but also after developing schizophrenia. The two-hit hypothesis claims that genetic or environmental vulnerabilities (first hit) for schizophrenia interact with additional genetic or environmental factor/s (second hit), such as substance abuse, resulting in the development of psychotic symptoms and schizophrenia [18]. In the two-hit hypothesis drug abuse both contributes to and exacerbates schizophrenia symptoms. Related to this is the shared susceptibility hypothesis, which suggests that poor functioning and the presence of poverty, victimization and toxic social environments in patients with schizophrenia accumulate to increase risk for developing substance abuse [19]. Due to the similarities between the two-hit hypothesis and the shared susceptibility hypothesis, we will evaluate environmental influences on substance abuse risk as part of the two-hit hypothesis. Clinical evidence mostly falls in favour of the primary addiction hypothesis and the two-hit hypothesis [12]; however, determining cause and effect can often be difficult in clinical samples due to the ethical implications of administering substances which increase psychotic symptoms to individuals with schizophrenia. Preclinical rodent models can thus facilitate our understanding of causative factors for substance abuse and schizophrenia comorbidity.

\subsection{Rodent models of schizophrenia}

Preclinical rodent models of schizophrenia can be used to better understand aspects of schizophrenia aetiology, pathophysiology, symptomology and neural function. While no model can encompass the full spectrum of neurological change within this uniquely human disorder, models can help us understand how specific genetic and environmental factors contribute to, and also interact to bring about the development of schizophrenia. Furthermore, rodent models allow us to more precisely investigate different hypotheses for substance abuse comorbidity in schizophrenia. This review will examine comorbidity between drug abuse and schizophrenia in the following classes of model:

\section{Genetic models}

Genetic models are generated by inserting, knocking down, deleting or mutating genes relevant to schizophrenia into the rodent genome [20]. Many genetic risk factors for schizophrenia are cumulative and explain a small amount (e.g. 1-2\% of variance) in terms of risk for schizophrenia; thus combinations of risk genes or gene-environment combinations can improve on these models. Nonetheless, these models often possess good construct validity for schizophrenia, as causal factors associated with schizophrenia risk are reproduced in these models [20].

\section{Neurodevelopmental models}

Schizophrenia can be conceptualised as a neurodevelopmental disorder [21], and manipulations during gestation, birth and early postnatal development are used to produce irreversible changes in central nervous system development. Examples of manipulations include lesions, disruption of neurogenesis during critical gestational periods, post-weaning social isolation and maternal immune activation [20]. Due to the high volume of data on the neonatal ventral hippocampal lesion (NVHL) model, we will address this separately to other neurodevelopmental models.

\section{Pharmacological models}

In patients with schizophrenia, biochemical aberrations of the dopamine, $\gamma$-amino-butyric acid (GABA), glutamate [e.g. abnormalities of $\mathrm{n}$-methyl-d-asparate (NMDA) receptors], and nicotinic receptor systems, as well as functional and structural changes in the brain are present [22]. Repeated administration of substances which disrupt these neurotransmitter systems including phencyclidine (PCP), ketamine, dizocilpine (MK-801), amphetamine and methamphetamine produces behavioural and brain abnormalities which resemble symptoms of schizophrenia [20]; however, the construct validity (i.e. the relevance of these pharmacological models to schizophrenia pathology) of these models is limited.

\subsection{Schizophrenia-relevant behaviour in rodents}

Schizophrenia-relevant behaviour can be modelled in rodents, and below we briefly describe behaviours modelling positive, negative and cognitive symptoms, as well as sensorimotor gating. For a more detailed review of this topic, see [20, 23, 24].

Positive symptoms of schizophrenia are modelled by tests of locomotor activity and sensitivity to effects of psychomimetic drugs on locomotion and stereotyped behaviours. Locomotor behaviour is considered a proxy measure for psychosis, as both locomotion and psychosis are elevated by increased dopamine transmission in the mesolimbic pathway, and both psychosis and hyperlocomotion in schizophrenia rodent models can be reduced by antipsychotic treatment [24]. Also, patients with schizophrenia are sensitive to the psychosis-inducing effects of psychomimetic drugs (e.g. amphetamines, the NMDA antagonist MK-801) [25], and these drugs can also increase locomotor behaviour. However, locomotion is a complex and nonspecific behaviour, and should be interpreted with caution, as compounds can reduce locomotor activity by mechanisms that may not be related to antipsychotic efficacy [24].

Negative symptoms of schizophrenia, such as anhedonia, social withdrawal and loss of motivation are measured through tests such as sucrose preference (modelling anhedonia), social interaction/social preference (modelling social withdrawal) and operant progressive ratio testing for food rewards (modelling loss of motivation) [23, 24]. Sucrose preference measures voluntary consumption of a palatable food reinforcer (i.e. sucrose) as well as water, and a reduction in preference for sucrose over 
water may indicate a limited ability to feel pleasure from a normally enjoyable activity. The social interaction test measures a range of behaviours exhibited when two unfamiliar rodents interact freely (e.g. sniffing the conspecific, following, climbing over/under etc). The social preference test assesses 1) preference for investigating an unfamiliar conspecific in a cage compared to an empty cage, and 2) preference for a novel conspecific over a familiar conspecific. While these social tests assess social behaviours, as well as the preference for socialisation and social novelty, the degree to which these directly correspond with social withdrawal in schizophrenia is not clear. Operant progressive ratio testing examines the motivation to obtain a food reward. Animals engage in an operant response (e.g. lever press, nose poke) to receive a food reward (e.g. sugar pellet), and throughout the session, the response requirements for the reward are increased, requiring more effort from the animal to obtain the food reward. This test is considered a measure of avolition, which can be impaired in schizophrenia [23, 24].

Cognitive impairment in schizophrenia, for example, deficits in working memory, attention, and executive function, are modelled through an array of rodent cognitive tasks. Most cognitive behavioural tasks reported in this review assess shortand long-term memory function, using tasks such as fear conditioning (animals learn to associate a tone and/or context with a footshock), the Morris Water Maze (animals learn to locate a platform submerged in water over successive days using either egocentric or environmental cues), novel object recognition test (animals investigate a novel object more than a familiar object) and Y-maze (animals investigate a novel arm in a Y-shaped maze more than familiar arms). However, there are more complex tests of cognitive ability which may better reflect cognitive impairment in schizophrenia. These include the 5 choice serial reaction time task, where animals in an operant chamber need to identify which of five apertures has been briefly illuminated, via a nose poke, to receive a food reward; this assesses attention and inhibitory control [24]. In the set shifting task, animals learn to dig for a food reward which is associated with specific cues. When tested, animals need to respond to relevant cues associated with a food reward (e.g. digging medium), and ignore cues which do not predict a food reward (e.g. odour); this assesses rule learning and discrimination [24]. Rodent touchscreen technology, in which rodents need to respond to 'target' visual pattern stimuli and to withhold responses to 'non-target' stimuli, permits assessment of perceptual discrimination, object-place associative learning, attention, impulsivity, compulsivity, extinction and other domains $[26,27]$.

A related domain is prepulse inhibition (PPI), a measure of sensorimotor gating, which is a pre-attentional process to facilitate stimulus filtering and limit sensory overload [28]. PPI is the reduction in startle to an auditory or tactile stimulus, by the prior presentation of a non-startling stimulus [28]. PPI is measured in rodents assessment of the whole body flinch to auditory (i.e. tone/white noise) or tactile (i.e. air puff) stimuli, and can be disrupted by administration of psychomimetic drugs [28]. PPI is impaired in patients with schizophrenia, but PPI deficits are also observed in other disorders e.g. obsessivecompulsive disorder, Tourette's syndrome; thus, PPI is not specific to schizophrenia alone [29].

\subsection{Addiction-relevant behaviour in rodents}

Here we briefly outline the behavioural assessment of addiction-relevant behaviour in rodents; however, further information on these tests can be found in the following reviews for conditioned place preference [28-31], behavioural/locomotor sensitization [32-34], and drug self- administration $[35,36]$.

Conditioned Place Preference (CPP): CPP is an indirect measure of drug reward, based on context-drug associations. The CPP apparatus contains two distinct environments (i.e. drugpaired and vehicle-paired environments), created by a combination of wall patterns, floor textures and/or scent cues. Animals are tested for their baseline preference between these two compartments, in a pre-test baseline session. Then, across several days, animals are given vehicle- and drugenvironment pairings (i.e. animals are given a vehicle injection and confined to the vehicle-paired environment in the morning, and then in the afternoon or the next day, animals are given a drug injection and confined to the drug-paired environment). This process is repeated several times (e.g. normally 3-5 vehicle and drug pairings for each animals). At Test, animals are given free access to both compartments, and if they spend more time in the drug-paired environment than the vehicle-paired environment, this indicates the drug was rewarding. The place preference score is often presented as the difference between pre- and post-test scores.

Behavioural/Locomotor Sensitization: Behavioural/locomotor sensitization is defined by the augmented motor-stimulant response that occurs with repeated, intermittent exposure to a drug, and is considered a marker of neural adaptations that can facilitate future drug taking [32]. Briefly, animals are intermittently administered a drug in a specific context (e.g. an open field apparatus). Repeated administration of the same drug dose over successive days/weeks leads to an increase in the behavioural response to the drug, termed the development of sensitization. These behaviours can include locomotion and/or stereotyped behaviours (e.g. sniffing, grooming, head weaving). Expression of sensitization is evident when animals are given a low-dose drug prime and they exhibit higher levels of these behaviours than in response to vehicle treatment (i.e. the behaviours have sensitized).

Intravenous drug self-administration: Rodents can selfadminister drugs of abuse freely within operant chambers, allowing control over the amount and frequency of the drug administered. Animals can engage in an operant response (e.g. lever press, nose poke, head movements detected by infra-red beams), which will provide a drug infusion. Drug reward can occur in the presence of cues (e.g. light, tone), and other discriminative stimuli (e.g. scents, wall and floor textures). An inactive operant response (e.g. lever press on the 'inactive' lever or nose poke in the 'inactive' hole) permits assessment of discrimination within the task. Rodents learn to self-administer abused drugs according to reinforcement schedules e.g. Fixed Ratio (FR) schedules require a fixed number of operant responses to obtain a drug reward (e.g. FR2 requires 2 lever presses for 1 drug reward), while a Progressive Ratio (PR) schedule requires an increasing number of operant responses to obtain a drug reward. After a period of selfadministration (often 2-3 weeks), animals can be put into abstinence (e.g. kept in home cage with no exposure to operant chambers) or undergo extinction training, where the drug is no longer available in the operant chambers, and animals need to learn to inhibit their responding on the active lever. Extinction can also be conducted in a different context, mimicking the change in context which can occur in rehabilitation centres. Drug-associated cues may also be omitted during extinction. Relapse-like behaviour can be modelled in reinstatement and renewal tests, where animals are returned to the operant chambers and drug-associated cues are presented (i.e. cueinduced reinstatement), or a low dose drug-prime is administered (i.e. drug-primed reinstatement), or the animals experience a stressor (i.e. stress-induced reinstatement). Renewal of drug-seeking occurs when an animal is extinguished in a different context, but is then returned to the original drug- 
taking context, which facilitates drug-seeking. Resumption of drug-taking can also be modelled after extinction; this is termed reacquisition.

Intracranial Self-Stimulation: In the intracranial selfstimulation (ICSS) paradigm, rodents are implanted with intracranial electrodes that target specific brain regions [e.g. medial forebrain bundle of the hypothalamus, ventral tegmental area (VTA)], and performance of an operant response results in the delivery of electrical stimulation to that target [37, 38]. ICSS is rewarding as it promotes dopamine release in nucleus accumbens, it is enhanced by drugs that increase extracellular dopamine in nucleus accumbens, and it is blocked by drugs that deplete dopamine or block dopamine receptors $[37,38]$. Rodents learn to stimulate the target brain region over several training days, and ICSS rates levels can modified by parameters such as pulse frequency, pulse amplitude, stimulus train duration and schedule of reinforcement [37]. In ICSS paradigms, ICSS rates are lower at low frequencies (e.g. 56-71 Hz) and increase with higher frequencies $(110 \mathrm{~Hz}+)$ [37]. The abuse potential of drugs can be assessed in ICSS: once animals have established baseline responding, administration of an abused drug can shift their baseline ICSS responding e.g. responding at low frequencies at baseline can be elevated by drug treatment [37]. The facilitation of ICSS responding is indicative of abuse potential; this may be due to ICSS and drug administration producing additive effects on mesolimbic dopamine release and transmission, thus facilitating the operant behaviour which maintains ICSS [37].

\subsection{Methods and literature}

During the course of writing this review, we noticed that interactions between abused substances and schizophrenia rodent models tended to target two major, yet distinct research questions. One question explored how rodent models of schizophrenia respond to drugs of abuse in addiction behavioural paradigms (e.g. conditioned place preference, locomotor sensitization, self-administration). This question evaluates the primary addiction hypothesis (i.e. that schizophrenia and drug addiction share similar pathophysiology in mesocortolimbic circuitry) and investigates if addiction behaviour is elevated in rodent models of schizophrenia, suggesting that risk for schizophrenia also elevates risk for substance abuse.

The other component of the literature addresses if animal models of schizophrenia are more susceptible to the effects of abused drugs on schizophrenia-relevant behaviour, including whether schizophrenia-like behaviour is exacerbated by abused drugs in rodent models of the disorder. This component addresses the two-hit hypothesis, and evidence in favour of this hypothesis suggests the development of schizophrenia may be facilitated by drug exposure. Alternatively, some studies also examine the possible therapeutic effects of some abused drugs in these models, potentially supporting the selfmedication hypothesis.

To provide a structured overview, each component of the review is divided into the model used and the drug investigated. In 2013, Ng and colleagues reviewed the existing literature on rodent models of schizophrenia targeting dual diagnosis [39], and we refer readers to this review for an in-depth examination of substance abuse comorbidity in rodent models of schizophrenia prior to 2013. However, since then a large body of literature has examined this topic further, providing novel insights into the behavioural and molecular underpinnings of comorbid substance abuse in schizophrenia. Here, we present literature since 2013 on this topic; yet, where relevant (e.g. when limited information is available on a topic), we refer to older studies to help inform our conclusions. Literature searches were con- ducted using PubMed. Our search terms are provided in Table 1.

\subsection{Definitions}

Here we outline several definitions used within this review.

Developmental periods: Susceptible periods of rodent development include the neonatal period [gestational day (G) 1$18 / 21$ ] and postnatal period [postnatal day (PND) 1-21], as well as adolescence (PND 22-60), young adulthood (PND 60-90) and adulthood (PND 90+). While there is discussion over the duration of adolescence in rodents [40], we have adopted these broad definitions, based on a review of the rodent adolescent literature [40], to provide consistency for the reader.

Drug administration: Drug administration is described as acute (once-off drug administration, often within 1 hour before or after experimental manipulation), sub-chronic (3-10 days drug administration; drugs are often administered $1-2 \mathrm{x}$ every 24 hours) or chronic (1-2 administrations per day for more than 10 days).

Schizophrenia-relevant behaviour: Schizophrenia-like behaviour can be modelled in rodents using tests to assess positive and negative symptoms, as well as cognitive impairment and sensorimotor gating deficits. These are described above in section 1.3 (reviews: $[24,41,42]$ ).

Addiction-relevant behaviour: We refer extensively to behavioural tests of addiction-relevant behaviour (described above in section 1.4), including conditioned place preference (CPP), behavioural/locomotor sensitization, and drug selfadministration.

\section{Addiction-relevant behaviour in rodent models of schizophrenia}

All preclinical studies reviewed in section 2 are summarised in Tables 2, 3 and 4 .

\subsection{Genetic models}

Addiction-like behaviour in genetic models of schizophrenia has been examined only for the psychostimulants cocaine and amphetamine, which increase dopamine release and transmission in the mesocorticolimbic pathway $[43,44]$.

\section{Psychostimulants: cocaine and amphetamine}

Dopamine metabolism and signalling are critically linked schizophrenia symptoms, whereby elevated dopamine release in the mesolimbic pathway is hypothesized to contribute to positive symptoms, whereas reduced dopamine in the mesocorticolimbic pathway appears to contribute to negative symptoms of the disorder $[45,46]$. Altered dopamine signalling may be linked to dopamine receptor expression, and several studies indicate $\mathrm{D}_{2}$ receptor expression is elevated in the striatum but reduced in thalamic regions of unmedicated patients with schizophrenia (review: [47]). Interestingly, mice overexpressing dopamine $\mathrm{D}_{2}$ receptors in the paraventricular nucleus of the hypothalamus (PVT) (i.e. the opposite of what is observed in patients with schizophrenia) show attenuated locomotor sensitization to a cocaine challenge, compared to mice which do not overexpress PVT $\mathrm{D}_{2}$ receptors [48], suggesting reduced susceptibility to cocaine-induced neural adaptations. These effects on cocaine sensitization occur in the absence of altered schizophrenia-relevant behaviours in PVT $\mathrm{D}_{2}$ overexpressing mice [48]. The PVT may modulate cocaine sensitization via dense projections to critical reward regions such as the medial prefrontal cortex (mPFC), nucleus accumbens (NAcc), 
Table 1. Search term keywords used in PubMed.

\begin{tabular}{lllll}
\hline Keyword 1 & Boolean operator & Keyword 2 & Boolean operator & Keyword 3 \\
\hline Schizophrenia [Title/Abstract] & AND & Mouse [Title/Abstract] & AND & Alcohol [Title/Abstract] \\
Schizophrenia [Title/Abstract] & AND & Mouse [Title/Abstract] & AND & Nicotine [Title/Abstract] \\
Schizophrenia [Title/Abstract] & AND & Mouse [Title/Abstract] & AND & Cannabis [Title/Abstract] \\
Schizophrenia [Title/Abstract] & AND & Mouse [Title/Abstract] & AND & Cocaine [Title/Abstract] \\
Schizophrenia [Title/Abstract] & AND & Mouse [Title/Abstract] & AND & Methamphetamine [Title/Abstract] \\
Schizophrenia [Title/Abstract] & AND & Rat [Title/Abstract] & AND & Cannabis [Title/Abstract] \\
Schizophrenia [Title/Abstract] & AND & Rat [Title/Abstract] & AND & Nicotine [Title/Abstract] \\
Schizophrenia [Title/Abstract] & AND & Rat [Title/Abstract] & AND & Alcohol [Title/Abstract] \\
Schizophrenia [Title/Abstract] & AND & Rat [Title/Abstract] & AND & Cocaine [Title/Abstract] \\
Schizophrenia [Title/Abstract] & AND & Rat [Title/Abstract] & AND & Addiction [Title/Abstract] \\
Schizophrenia [Title/Abstract] & AND & Mouse [Title/Abstract] & AND & Substance Abuse [Title/Abstract] \\
Schizophrenia [Title/Abstract] & AND & Mouse [Title/Abstract] & AND & Addiction [Title/Abstract] \\
Schizophrenia [Title/Abstract] & AND & Rat [Title/Abstract] & AND & Substance Abuse [Title/Abstract] \\
Schizophrenia [Title/Abstract] & AND & Rat [Title/Abstract] & AND & Addiction [Title/Abstract] \\
Schizophrenia [Title/Abstract] & AND & Rodent [Title/Abstract] & AND & Drug abuse [Title/Abstract] \\
Schizophrenia [Title/Abstract] & AND & Rodent [Title/Abstract] & &
\end{tabular}

amygdala and bed nucleus of the stria terminalis (BNST). The effects of $D_{2}$ receptor knockdown/knockout in the PVT have not yet been examined; however, it would be interesting to observe whether reduced PVT $\mathrm{D}_{2}$ expression increases cocaine sensitization and other addiction-relevant behaviours, potentially providing a mechanism for elevated drug abuse susceptibility in patients with schizophrenia.

The DISC1 gene is a rare genetic risk factor for schizophrenia that codes for several proteins involved in dopamine signalling (e.g. CAMP-specific 3',5'-cyclic phosphodiesterase 4B, serine/threonine protein kinase Akt and glycogen synthasekinase3 (GSK-3) $[49,50])$. Several lines of transgenic mice designed to model DISC 1 mutations have been created, many of which exhibit schizophrenia relevant behaviours, including hyperactivity, decreased social behaviours, anhedonia in the sucrose preference test and sensorimotor gating impairment (review: [51]). Recent evidence suggests DISC1 gene alterations can regulate addiction-relevant behaviour for cocaine in rats [52]. Disc1 knockdown in the NAcc of rats increases cocaine self-administration under higher reinforcement schedules [i.e. FR4-10, but not FR1-2] [52]. Also,DISC1 protein levels are elevated in the NAcc of sham control rats after 12 days of cocaine self-administration, compared to sham control rats which selfadminister saline [52]. This suggests Disc1 can regulate motivation for cocaine, and upregulation of DISC 1 protein may be a compensatory mechanism following repeated cocaine selfadministration. Importantly, this provides a link between genetic risk for schizophrenia and drug addiction susceptibility, supporting the primary addiction hypothesis.

Epidermal growth factor (EGF) is involved in cellular proliferation, differentiation, and survival, and a functional single nucleotide polymorphism (SNP) in the EGF gene which increases EGF transcription is associated with lower age of onset of schizophrenia [53,54]. EGF overexpression in mice facilitates acquisition of cocaine behavioural sensitization, such that cocaine sensitization is much stronger in mice overexpressing EGF, compared to wildtype-like (WT) controls where sensitization did occur but was not very prominent [55]. These behavioural effects are accompanied by changes in dopamine metabolites in mice overexpressing EGF: striatal extracellular levels of tyrosine hydroxylase (TH) are decreased and catechol-O-methyl-transferase (COMT) increased, whereas dopa-decarboxylase in the NAcc and frontal cortex are increased, and extracellular dopamine and DOPAC are elevated in the NAcc [55]. These findings link increased EGF function with elevated cocaine sensitivity via increased dopamine metabolism, and also supports the primary addiction hypothe- sis.

NMDA receptors regulate glutamate signalling which appears to be dysregulated in schizophrenia, and NMDA dysfunction is observed in post mortem brain tissue of patients with schizophrenia [56]. Changes to NMDA function can be modelled using glycine transporter 1 heterozygous knockout mice to model NMDA hyperfunction, and serine racemase knockout to model NMDA hypofunction [57]. Glycine transporter 1 heterozygous knockout in the forebrain (i.e. forebrain NMDA hyperfunction) enhances cognitive performance in mice $[58,59]$, while serine racemase knockout mice (i.e. NMDA hypofunction) exhibit hyperlocomotion, sociability deficits and greater ventricular volumes [60-62], all of which are relevant to schizophrenia. In terms of drug abuse potential, both NMDA hyper- and hypofunction mouse models express place preference for cocaine [57]. However, NMDA hypofunction facilitates extinction of cocaine place preference (i.e. NMDA hypofunction reduces drug seeking), whereas NMDA hyperfunction enhances drug-primed reinstatement of cocaine place preference (i.e. NMDA hyperfunction increases drug seeking) [57]. In addition, NMDA hypofunction reduces sensitivity to the thresholdlowering (i.e. rewarding) and the performance-elevating (i.e. stimulant) effects of cocaine in an intracranial self-stimulation paradigm [63]. NMDA hypofunction also attenuates cocaine locomotor sensitization [57]; this may be due to blunted cocaineinduced dopamine and glutamate release in the NAcc [63]. Note also that a previous study reported that NMDA hypofunction reduces expression of context-specific sensitization and conditioned hyperactivity for amphetamine, while NMDA hyperfunction facilitates acquisition of amphetamine sensitization [64]. Together, this suggests that NMDA receptor hypofunction decreases the rewarding responses of cocaine, and higher doses of cocaine are required to achieve a hedonic response, while NMDA hyperfunction increases cocaine reward and necessitates lower doses of cocaine for a hedonic response. Considering NMDA receptors appear downregulated in schizophrenia, particularly in reward-relevant regions such as the striatum and prefrontal cortex (review: [56]), it seems that individuals with schizophrenia may require higher doses of cocaine to achieve a rewarding state, increasing the risk of developing severe physiological dependency and withdrawal [63].

Together, these studies demonstrate addiction-like behaviour in genetic models of schizophrenia risk. In particular, genetic models with construct validity for schizophrenia e.g. Disc1 and EGF transgenic mice, exhibit enhanced addictionlike behaviour, providing support for the primary addiction hypothesis. Furthermore, EGF transgenic mice exhibit elevated 
Table 2. Addiction-relevant behaviour in genetic and pharmacological rodent models of schizophrenia

\begin{tabular}{|c|c|c|c|c|}
\hline $\begin{array}{l}\text { Author, date [Refer- } \\
\text { ence] }\end{array}$ & Model & Drug & $\begin{array}{l}\text { Results - Behaviour ( } \downarrow \text { decrease, } \\
\uparrow \text { increase, } \sim \text { no effect) }\end{array}$ & $\begin{array}{l}\text { Results - Brain ( } \downarrow \text { decrease, } \\
\uparrow \text { increase, } \sim \text { no effect) }\end{array}$ \\
\hline Clark et al 2017 [48] & $\begin{array}{l}\mathrm{DA}_{2} \text { receptor over- } \\
\text { expression in the } \\
\text { PVT of mice }\end{array}$ & Cocaine & $\downarrow$ cocaine sensitization. & $\mathrm{n} / \mathrm{a}$ \\
\hline $\begin{array}{l}\text { Gancarz et al } 2016 \\
\text { [52] }\end{array}$ & $\begin{array}{l}\text { Disc1 knockdown in } \\
\text { the Nacc of rats }\end{array}$ & Cocaine & $\uparrow$ cocaine self-administration. & $\begin{array}{l}\uparrow \text { Nacc DISC1 protein levels after } \\
\text { cocaine self-administration in } \\
\text { shams. }\end{array}$ \\
\hline Eda et al 2013 [55] & $\begin{array}{l}\text { EGF overexpressing } \\
\text { mice }\end{array}$ & Cocaine & $\uparrow$ cocaine sensitization. & $\begin{array}{l}\text { in EGF overexpressing mice: } \\
\downarrow \text { striatal extracellular tyrosine } \\
\text { hydroxylase, } \uparrow \text { catechol-O- } \\
\text { methyl-transferase. } \\
\uparrow \text { dopa-decarboxylase in Nacc } \\
\text { and FC. } \uparrow \text { Nacc extracellular } \\
\text { dopamine and dopamine } \\
\text { metabolites. }\end{array}$ \\
\hline Puhl et al $2015[60]$ & $\begin{array}{l}\text { Glycine transporter } \\
1 \text { HET knockout } \\
\text { mice }\end{array}$ & Cocaine & $\begin{array}{l}\sim \text { cocaine CPP and CPP extinction. } \\
\uparrow \text { Cocaine-primed reinstatement. }\end{array}$ & $\mathrm{n} / \mathrm{a}$ \\
\hline $\begin{array}{l}\text { Puhl et al } 2015 \text { [60]; } \\
\text { Puhl et al } 2019 \text { [63] }\end{array}$ & $\begin{array}{l}\text { Serine racemase } \\
\text { knockout mice }\end{array}$ & Cocaine & $\begin{array}{l}\sim \text { cocaine CPP. } \uparrow \text { cocaine CPP } \\
\text { extinction. } \downarrow \text { cocaine } \\
\text { sensitization. } \downarrow \text { sensitivity to } \\
\text { cocaine ICSS. }\end{array}$ & $\begin{array}{l}\downarrow \text { cocaine-induced dopamine and } \\
\text { glutamate release in NAcc. }\end{array}$ \\
\hline $\begin{array}{l}\text { Benneyworth et al } \\
2012 \text { [64] }\end{array}$ & $\begin{array}{l}\text { Glycine transporter } \\
1 \text { HET knockout } \\
\text { mice }\end{array}$ & Amphetamine & $\begin{array}{l}\text { Tamphetamine sensitization. } \\
\text { expression of amphetamine } \\
\text { sensitization. }\end{array}$ & $\mathrm{n} / \mathrm{a}$ \\
\hline $\begin{array}{l}\text { Benneyworth et al } \\
2012 \text { [64] }\end{array}$ & $\begin{array}{l}\text { Serine racemase } \\
\text { knockout mice }\end{array}$ & Amphetamine & $\begin{array}{l}\downarrow \text { Amphetamine sensitization and } \\
\downarrow \text { expression of amphetamine } \\
\text { sensitization. } \downarrow \text { Extinction of } \\
\text { amphetamine sensitization. }\end{array}$ & $\begin{array}{l}\uparrow \text { NAcc spine density after } \\
\text { extinction. }\end{array}$ \\
\hline $\begin{array}{l}\text { Fletcher et al } 2018 \\
\text { [110] }\end{array}$ & $\begin{array}{lr}\text { Chronic } & \text { am- } \\
\text { phetamine } & \text { treat- } \\
\text { ment in rats } & \end{array}$ & Nicotine & $\begin{array}{l}\sim \text { Acquisition and maintenance of } \\
\text { nicotine self-administration. }\end{array}$ & $\mathrm{n} / \mathrm{a}$ \\
\hline $\begin{array}{l}\text { Fletcher et al } 2018 \\
\text { [110] }\end{array}$ & $\begin{array}{l}\text { Chronic PCP treat- } \\
\text { ment in rats }\end{array}$ & Nicotine & $\begin{array}{l}\sim \text { Acquisition and maintenance of } \\
\text { nicotine self-administration. }\end{array}$ & $\mathrm{n} / \mathrm{a}$ \\
\hline
\end{tabular}

Abbreviations: CPP, conditioned place preference; DA, dopamine; Disc1; Disrupted in Schizophrenia 1; EGF, epidermal growth factor; FC, frontal cortex; HET; heterozygous; ICSS, intracranial self-stimulation; NAcc, nucleus accumbens, PCP, phencyclidine.

dopamine metabolism in forebrain regions, and considering the critical role of dopamine in reward signalling, these models provide a potential mechanism for elevated addiction propensity in individuals with schizophrenia. Future research will examine addiction-relevant behaviours in other genetic models of schizophrenia, to non-psychostimulant drugs.

\subsection{Lesion models}

The neonatal ventral hippocampal lesion (NVHL) is a widely used neurodevelopmental animal model, in which an excitotoxin infusion is made into the ventral hippocampus during the first postnatal week, a time point roughly comparable to the third trimester of human development [65]. This lesion causes neurodevelopmental interruptions hypothesised to be relevant to schizophrenia susceptibility [66]. The NVHL model develops behavioural and neurobiological dysfunction relevant to schizophrenia e.g. social interaction and cognitive impairment, prepulse inhibition deficits, and an enhanced locomotor response to stress $[67,68]$.

\section{Psychostimulants: amphetamine and methamphetamine}

In a brain stimulation paradigm in young adult rats, reward thresholds following acute amphetamine are similarly elevated in NVHL and sham controls, yet this elevation drops off more rapidly in NVHL rats, indicating increased tolerance for amphetamine [69]. In a drug self-administration paradigm,
NVHL rats show higher motivation for methamphetamine selfadministration under a progressive ratio schedule, but no differences in responding under a fixed ratio schedule of reinforcement [70].

\section{Psychostimulants: cocaine}

Cocaine-induced locomotor activity during sensitization, as well as locomotion following a cocaine challenge is enhanced in adult NVHL rats compared to sham controls $[71,72]$. However, when examining gene expression in the caudate-putamen and mPFC using genome-wide microarrays, there is no overlap in the direction of gene expression change induced by NVHL and cocaine sensitization i.e. NVHL mostly downregulates gene expression in these regions, whereas cocaine sensitization mostly upregulates gene expression, compared to sham controls [71]. This analysis included genes associated with neuropsychiatric conditions (e.g. psychosis, bipolar disorder), such as Estrogen receptor 2, Glial fibrillary acidic protein, $C D 40$ molecule TNF receptor Superfamily 5 , and several Zinc finger protein genes. There were a limited number of genes ( $17 \%$ of total genes) impacted on by NVHL-cocaine interactions, and there was no overlap in the direction of gene expression change for these interactions [71]. The rarity of convergence of NVHL and cocaine sensitization effects on individual genes suggests that the NVHL model and cocaine treatment may interact on the neural network level, rather than being reducible to one or a few molecular interactions [71].

Cocaine self-administration under fixed ratio responding is 
intact in NVHL rats, yet lesioned rats demonstrate prolonged extinction and exaggerated cue-induced reinstatement of cocaine seeking, suggesting impaired prefrontal control over cueinduced drug-seeking or a general impairment in new actionoutcome learning [73]. Supporting this, working memory deficits in the radial arm maze in adult NVHL rats predict subsequent cocaine behavioural sensitization, suggesting a link between cognition and addiction-relevant behaviours in this model [72]. However, incubation of cocaine craving is not altered in NVHL rats, suggesting specific addiction-relevant behavioural domains are altered following NVHL lesions [73]. Collectively, this suggests NVHL rats model several aspects of increased susceptibility to psychostimulant abuse observed in individuals with schizophrenia, and suggest changes in gene expression may interact at a neural network level to facilitate drug-seeking behaviour.

\section{Nicotine}

Nicotine abuse is very common in schizophrenia - up to $90 \%$ of patients smoke cigarettes compared to approximately $26 \%$ of the general population [5]. Animal models have the potential to unravel this high level of susceptibility to nicotine.

Neonatal ventral hippocampal lesions enhance the rewarding effects of nicotine. Adult NVHL rats demonstrate faster acquisition of nicotine self-administration and higher nicotine intake during self-administration ([74] but see also [72, 75]), modelling the higher levels of smoking observed in schizophrenia patients. Adult NVHL rats are also resistant to reducing nicotine use, exhibiting slower extinction of nicotine seeking and elevated drug-primed reinstatement compared to sham controls $[72,74,75]$.

Increased susceptibility to nicotine may be age-dependent, occurring only in adult NVHL but not adolescent NVHL rats. Nicotine sensitization in adolescence is similar between NVHL and sham controls [74]. Furthermore, prior nicotine sensitization does not affect acquisition or extinction of nicotine selfadministration, suggesting adolescent nicotine treatment does not facilitate later nicotine consumption [74]. While nicotine sensitization increases responding for a high nicotine dose (30 $\mu \mathrm{g}$ /infusion, dose-response study), this is unaffected by NVHL [74]. Together, this data suggests that schizophrenia pathology may precipitate vulnerability to nicotine addiction later in life, but early nicotine exposure does not modulate this relationship.

Interestingly, when both ethanol and nicotine are available in a self-administration paradigm, NVHL rats display greater consumption of both ethanol and nicotine compared to sham controls [75]. During extinction, when both ethanol and nicotine are unavailable, NVHL rats exhibit elevated responding for these two drugs, compared to sham controls [75]. Drugprimed reinstatement of nicotine-seeking is greater in NVHL rats compared to sham controls, but this is unaffected by ethanol availability [75]. These findings indicate vulnerability of NVHL rats to both substances when they are concurrently available.

\section{Ethanol}

Alcohol abuse is also observed at higher rates in schizophrenia (43-65\% of patients experience alcohol dependence) than in the general population (approximately 5\%) [5]. Adolescent alcohol use is associated with elevated use in adulthood in healthy controls [76]; however, susceptibility to the effects of adolescent alcohol use on brain reward dysfunction is unknown in schizophrenia. NVHL rats can be used to model this relationship. Indeed, NVHL rats are susceptible to adolescent ethanol exposure: NVHL rats given chronic voluntary ethanol access during adolescence demonstrate higher rates of ethanol consumption in two-bottle free choice in adulthood compared to sham controls given voluntary ethanol access in adolescence. NVHL rats with adolescent ethanol access also show escalation of ethanol self-administration, delayed extinction of ethanol-seeking and higher rates of drinking during reacquisition compared to sham controls with adolescent ethanol access [77]. These effects occur despite similar levels of adolescent ethanol intake between NVHL and sham rats, and importantly, addiction-like phenotypes (e.g. escalation of intake, resistance to extinction) are only present in NVHL rats which experience adolescent exposure to ethanol [77]. These findings indicate that NVHL lesions do not have an impact on the immediate effect of ethanol in adolescence but increase later susceptibility for addictive-like behaviour, supporting a two-hit model of addiction susceptibility i.e. early drug exposure and schizophrenia/addiction susceptibility increases risk for addiction in later life.

For a natural reinforcer (e.g. sucrose), in a selfadministration paradigm, NVHL rats show intact extinction learning, and reacquisition of responding is similar to controls [77]. NVHL rats do however exhibit impaired acquisition and maintenance of autoshaping for a food reinforcer following latent inhibition, and impaired extinction of autoshaping behaviour [78], suggesting select cognitive deficits in this model. Interestingly, these cognitive deficits may contribute to the ethanol addiction-relevant phenotype of NVHL rats, as the degree of latent inhibition in NVHL rats predicts future ethanol drinking [78], suggesting a link between cognitive impairment and elevated ethanol consumption in this model.

Cannabinoids: $\quad C_{1}$ receptor agonists WIN 55,212-2 and $\Delta^{9-}$ tetrahydrocannabinnol

$\mathrm{CB}_{1}$ cannabinoid receptor agonists are of particular relevance to schizophrenia because $C_{1}$ receptors mediate the psychoactive and rewarding properties of cannabis [79], and there is strong evidence linking adolescent cannabis use with increased risk for schizophrenia, particularly in individuals with genetic predisposition for the disorder (reviews: [80, 81]). In addition, cannabis abuse is $3-4 \mathrm{x}$ higher in patients with schizophrenia than in healthy populations [5]. Assessing addiction-relevant behaviours for $\mathrm{CB}_{1}$ receptor agonists in schizophrenia rodent models can provide insights into why cannabis use is so common in schizophrenia. It should be noted that in many rodent studies, $\mathrm{CB}_{1}$ receptor agonists fail to produce rewarding and reinforcing effects [82-84], or only do so under specific experimental conditions, which may be due to concurrently occurring aversive properties of these drugs mediated by effects of cannabinoids on other receptors (e.g. in mice, $\mathrm{k}$-opioid receptors mediate aversive effects of THC); see discussion in [84].

NVHL rats exhibit an age-specific susceptibility to the $\mathrm{CB}_{1}$ receptor agonist WIN 55,212-2 (WIN) [85]. While acute WIN treatment has no effect on locomotion in adolescence in NVHL rats, WIN increases locomotor activity in young adult NVHL rats, compared to sham controls [85]. In addition, young adult but not adolescent NVHL rats exhibit a greater aversion to WIN in a conditioned place preference paradigm compared to controls, yet the opposite effect occurs for $\mathrm{CB}_{1}$ receptor agonist $\Delta^{9}$-tetrahydrocannabinnol (THC), where sham controls demonstrate an aversion for THC, which is not present in NVHL rats [85]. These findings are mirrored in a brain stimulation reward paradigm, where THC produces a weak attenuation of reward in sham controls, but not NVHL rats, and WIN has the opposite effect, attenuating reward in NVHL rats but enhancing it in controls [69]. The different effects of THC and WIN may be due to different pharmacokinetics between the two drugs (e.g. WIN has a higher $\mathrm{CB}_{1}$ receptor affinity than THC [86]), and/or cannabinoid receptor expression in reward regions [(e.g. striatum, VTA] in NVHL rats, but this has not been assessed. Nonetheless, together this suggests NVHL alters the sensitivity 
of the endocannabinoid system to reward, in a manner specific to the reinforcer used (e.g. NVHL increases sensitivity to WIN, but decreases sensitivity to THC).

\subsection{Non-lesion neurodevelopmental models}

Non-lesion neurodevelopmental models of schizophrenia induce a pre- or post-natal insult via maternal cytokine elevation [e.g. administration of mitotoxin methylazoxymethanol acetate (MAM), lipopolysaccharide (LPS), polyinosinic-citidilic acid (Poly I:C) or quinpirole], prenatal stress or rearing environment manipulations during the post-natal period. Pups tested in adolescence and/or adulthood show altered addictionrelevant behaviour to several drugs of abuse. It should be noted that the timing of maternal infection and the infectious agent chosen can influence behavioural and neurological outcomes, and the current lack of consistency across research groups in the implementation of maternal infection may cause differences in the outcomes $[87,88]$.

\section{Psychostimulants: amphetamine}

Altered dopaminergic function is observed in the Poly I:C model, where prenatal Poly I:C treatment in mice enhances locomotor sensitization and stereotyped behaviour to repeated amphetamine administration, compared to control offspring [89]. Also, amphetamine CPP is greater in Poly I:C offspring compared to control offspring, suggesting heightened reward for amphetamine [89]. Similarly, prenatally MAM-treated rats show a greater stereotyped behavioural response to an amphetamine challenge dose than controls, suggesting greater expression of amphetamine sensitization following prenatal MAM treatment [90]. This suggests maternal infection can increase sensitivity to the rewarding and locomotor stimulating effects of psychostimulants, and may suggest heightened dopaminergic system function.

\section{Psychostimulants: cocaine}

Mice prenatally exposed to Poly I:C exhibit enhanced cocaine reward in $\mathrm{CPP}$, indicating stronger cocaine context-reward associations [91]. Despite elevated cocaine context-reward associations, Poly I:C treated mice exhibit reduced cocaine-induced locomotor activity, which may indicate lower dopamine transporter or dopamine receptor availability in brain regions such as the VTA or striatum [91]. Prenatal Poly I:C treatment in rats also enhances cross-sensitization to cocaine after behavioural sensitization to amphetamine, suggesting elevated susceptibility to other stimulant drugs following repeated amphetamine administration [89]. Interestingly, Poly I:C mice do not exhibit place preference for a natural reward, sucrose, where control mice do, yet learning about an aversive stimulus (i.e. fear conditioning) is intact, suggesting impaired processing of appetitive reward in this model [91]. Collectively, this suggests increased susceptibility to stimulant reward in Poly I:C treated animals, but disrupted reward processing for natural rewards, which may reflect distinct neuronal changes (e.g. within the PFC-NAcc glutamate pathway and/or downstream in medium spiny neurons) that occur following exposure to drug vs natural rewards [92].

In rats which experience early life adversity [i.e. limited bedding and nesting (LBN) during PND 2-9], cocaine sensitization is unaffected. However, acute cocaine administration increases c-Fos expression in reward regions such as the NAcc core, central amygdala and lateral habenula of LBN rats, compared to controls [93]. c-Fos expression in orexin/hypocretin neurons following acute cocaine in LBN rats is decreased in the lateral, dorsomedial and perifornical regions of hypothalamus, suggesting reorganization of drug reward and stress circuitry following early life stress [93].

Despite elevated neuronal activity in reward regions following acute cocaine [93], cocaine self-administration behaviours are mostly unaltered in neurodevelopmental models of schizophrenia. While LBN rats initially acquire cocaine selfadministration faster than controls, LBN rats self-administer similar amounts of cocaine as controls after 10 days of training, and exhibit similar sensitivity to different cocaine doses [93]. Cocaine extinction and reinstatement of cocaine-seeking are also unaltered in LBN rats [93]. Interestingly, the hedonic set point for cocaine is reduced, such that LBN rats prefer to self-administer lower doses of cocaine under low effort conditions but demonstrated similar levels of motivation to selfadminister cocaine under higher effort conditions [93]. This suggests either a degree of cocaine anhedonia in LBN rats or that LBN rats reach cocaine satiety faster than controls, and suggests limited bedding and nesting does not increase cocaine addiction-like behaviours.

In the MAM neurodevelopmental model of maternal infection, there are no differences in cocaine self-administration under fixed and progressive schedules of reinforcement, nor in extinction or drug-induced reinstatement for cocaine [94]. Similarly, offspring of dams treated with LPS show unaltered cocaine self-administration, dose-response curves and extinction, despite working memory and sensorimotor gating impairment in this model [95]. Acute locomotor activity in response to various doses of cocaine is unaltered in MAM rats, compared to controls [94].

Together, this demonstrates sensitivity to cocaine addiction-relevant behaviours is highly dependent on the neurodevelopmental model used, for while Poly I:C treatment seems to increase cocaine reward and cross-sensitization, other neurodevelopmental models e.g. LBN, MAM, prenatal LPS, do not exhibit a cocaine addiction-like phenotype, or demonstrate a phenotype which suggests reduced susceptibility to cocaine (e.g. LBN show cocaine anhedonia).

\section{Psychostimulants: methamphetamine}

There are limited effects of prenatal MAM treatment on methamphetamine responses in offspring. Prenatal MAM treatment does not affect methamphetamine selfadministration under an FR1 schedule of reinforcement, or cueinduced reinstatement after abstinence, in male or female rats [96]. Dose-response, schedules of reinforcement and extinction behaviour for methamphetamine have not yet been examined in MAM rats. However, MAM offspring are less susceptible to the suppressing effects of low dose ketamine on methamphetamine self-administration than control rats, and the authors suggest this may be due to impaired PFC glutamatergic signalling in MAM rats [97]. Further research into the effects of neurodevelopmental insults on addiction behaviour for methamphetamine are warranted.

\section{Nicotine}

Developmental stress appears to increase sensitivity to nicotine. Adult rats which experienced prenatal stress exhibit greater nicotine reward in CPP than offspring of non-stressed rats [98]. Also, rats reared in isolation during adolescence show behavioural sensitization to repeated nicotine administration during adolescence, where rats reared in an enriched environment do not [99]. LPS treatment during gestation facilitates intravenous nicotine self-administration at higher reinforcement schedules (i.e. FR5, not FR1/FR2), but has no subsequent effects on dose-response responding or motivation for nicotine under a progressive ratio [100]. Similarly, in the MAM rat model of schizophrenia, Weeks and colleagues found no differences between MAM rats and controls in nicotine selfadministration [101]. This was observed across a range of doses 
Table 3. Addiction-relevant behaviour in neonatal ventral hippocampal lesion rat models of schizophrenia

\begin{tabular}{|c|c|c|c|c|}
\hline $\begin{array}{l}\text { Author, date [Refer- } \\
\text { ence] }\end{array}$ & Model & Drug & $\begin{array}{l}\text { Results - Behaviour ( }(\text { decrease, } \\
\uparrow \text { increase, } \sim \text { no effect })\end{array}$ & $\begin{array}{l}\text { Results } \quad-\quad \text { Brain } \\
\uparrow \text { increase, } \sim \text { no effect })\end{array}$ \\
\hline Gallo et al 2014 [69] & NVHL rat & Amphetamine & $\begin{array}{l}\uparrow \text { tolerance for amphetamine in } \\
\text { ICSS. }\end{array}$ & $\mathrm{n} / \mathrm{a}$ \\
\hline Brady et al 2008 [70] & NVHL rat & Methamphetamine & $\begin{array}{l}\sim \text { methamphetamine } \\
\text { self-administration (dose range). }\end{array}$ & $\mathrm{n} / \mathrm{a}$ \\
\hline $\begin{array}{l}\text { Chambers et al } 2013 \\
\text { [71]; Rao et al } 2016 \text { [72] }\end{array}$ & NVHL rat & Cocaine & $\begin{array}{l}\uparrow \text { Cocaine sensitization and } \\
\uparrow \text { expression of cocaine } \\
\text { sensitization. }\end{array}$ & $\begin{array}{l}\sim \text { gene expression change in stria- } \\
\text { tum and mPFC after cocaine sensi- } \\
\text { tization in NVHL. }\end{array}$ \\
\hline Karlsson et al 2013 [73] & NVHL rat & Cocaine & $\begin{array}{l}\sim \text { Cocaine self-administration. } \\
\downarrow \text { Extinction and } \uparrow \text { cue-induced } \\
\text { reinstatement for cocaine. } \\
\sim \text { Incubation of cocaine craving }\end{array}$ & $\mathrm{n} / \mathrm{a}$ \\
\hline $\begin{array}{l}\text { Rao et al } 2016[72] ; \\
\text { Berg et al } 2014[74] ; \\
\text { Sentir et al } 2018[75]\end{array}$ & NVHL rat & Nicotine & $\begin{array}{l}\sim \text { Nicotine sensitization. } \sim \text { Nicotine } \\
\text { sensitization on acquisition or } \\
\text { extinction of nicotine } \\
\text { self-administration. Nicotine } \\
\text { sensitization in NVHL } \uparrow \text { 's nicotine } \\
\text { self-administration, } \downarrow \text { extinction } \\
\text { and } \uparrow \text { nicotine-primed } \\
\text { reinstatement. }\end{array}$ & $\mathrm{n} / \mathrm{a}$ \\
\hline Sentir et al 2018 [75] & NVHL rat & Nicotine & $\begin{array}{l}\uparrow \text { Ethanol and nicotine } \\
\text { self-administration (when } \\
\text { available together). } \downarrow \text { Extinction of } \\
\text { nicotine and ethanol. } \\
\uparrow \text { Nicotine-primed reinstatement. }\end{array}$ & $\mathrm{n} / \mathrm{a}$ \\
\hline $\begin{array}{l}\text { Jeanblanc et al } 2015 \\
\text { [77] }\end{array}$ & NVHL rat & Ethanol & $\begin{array}{l}\text { Following adolescent ethanol } \\
\text { exposure, NVHL show } \uparrow \text { ethanol } \\
\text { free consumption, } \uparrow \text { escalation of } \\
\text { ethanol self-administration, } \\
\downarrow \text { extinction and } \uparrow \text { reacquisition of } \\
\text { ethanol. }\end{array}$ & $\mathrm{n} / \mathrm{a}$ \\
\hline $\begin{array}{l}\text { Jeanblanc et al } 2015 \\
\text { [77]; Khokhar et al } \\
2018[78]\end{array}$ & NVHL rat & Sucrose & $\begin{array}{l}\sim \text { Extinction and } \sim \text { reacquisition for } \\
\text { sucrose. } \downarrow \text { acquisition and } \\
\text { maintenance of autoshaping } \\
\text { following latent inhibition. } \\
\downarrow \text { Impaired extinction of } \\
\text { autoshaping behaviour for sucrose. }\end{array}$ & $\mathrm{n} / \mathrm{a}$ \\
\hline $\begin{array}{l}\text { Gallo et al } 2014 \text { [69]; } \\
\text { Gallo et al } 2014 \text { [85] }\end{array}$ & NVHL rat & WIN & $\begin{array}{l}\text { In NVHL, } \uparrow W I N-\text { induced } \\
\text { locomotion in young adulthood. } \\
\downarrow \text { WIN CPP in young adult NVHL. } \\
\text { WIN } \downarrow \text { ICSS reward in NVHL. }\end{array}$ & $\mathrm{n} / \mathrm{a}$ \\
\hline $\begin{array}{l}\text { Gallo et al } 2014 \text { [69]; } \\
\text { Gallo et al } 2014 \text { [85] }\end{array}$ & NVHL rat & THC & $\begin{array}{l}\downarrow \text { THC CPA in early adult NVHL. } \\
\sim \text { THC CPP in adolescent NVHL. } \\
\sim \text { THC ICSS in NVHL. }\end{array}$ & $\mathrm{n} / \mathrm{a}$ \\
\hline
\end{tabular}

Abbreviations: CPA, conditioned place aversion; CPP, conditioned place preference; ICSS, intracranial self-stimulation; mPFC, medial prefrontal cortex; NVHL, neonatal ventral hippocampal lesion; WIN, WIN 55,212-2.

and schedules of reinforcement, in both standard 1-hr selfadministration sessions and 23-hr extended access sessions, and this was not different between the sexes [101]. Interestingly, MAM animals responded less for sucrose or reinforcing visual stimuli alone or when paired with nicotine, suggesting potential deficits in reinforcement learning in this model [101]. Thus, it seems that developmental stress can increase susceptibility to nicotine addiction-like behaviour in adulthood, but this is not the case following maternal infection.

NAcc dopamine $\mathrm{D}_{2}$ receptor mRNA expression levels are elevated in adult rats which are prenatally stressed [98], while chronic postnatal quinpirole treatment, which increases $\mathrm{D}_{2}$ receptor sensitivity, enhances sensitization during adolescence to nicotine [99]. This suggests elevated $D_{2}$ receptor function may underlie effects of prenatal stress on nicotine reward. Importantly, elevations in $\mathrm{D}_{2}$ mRNA expression induced by prenatal stress are reduced by sub-chronic ( 8 day) nicotine treatment during adulthood [98], suggesting this effect may be reversible and potentially supporting the self-medication hypothesis.

Chronic nicotine treatment also increases glial cell linederived neurotrophic factor (GDNF) levels in the NAcc, and neonatal quinpirole reduces elevated GDNF levels induced by nicotine in isolation-reared rats [99]. Considering GDNF is critical for dopaminergic plasticity in reward-relevant brain regions [102], it is possible that elevated sensitivity to nicotine in neurodevelopmental rodent models of schizophrenia may be due to altered dopamine receptor function in reward regions (e.g. NAcc).

\section{Ethanol}

Recently, Ruda-Kucerova and colleagues found no differences in ethanol consumption using a voluntary consumption procedure or resumption of ethanol drinking after abstinence in male or female rats exposed to MAM prenatally [96]. However, other preclinical studies (pre-2013) have shown that early 


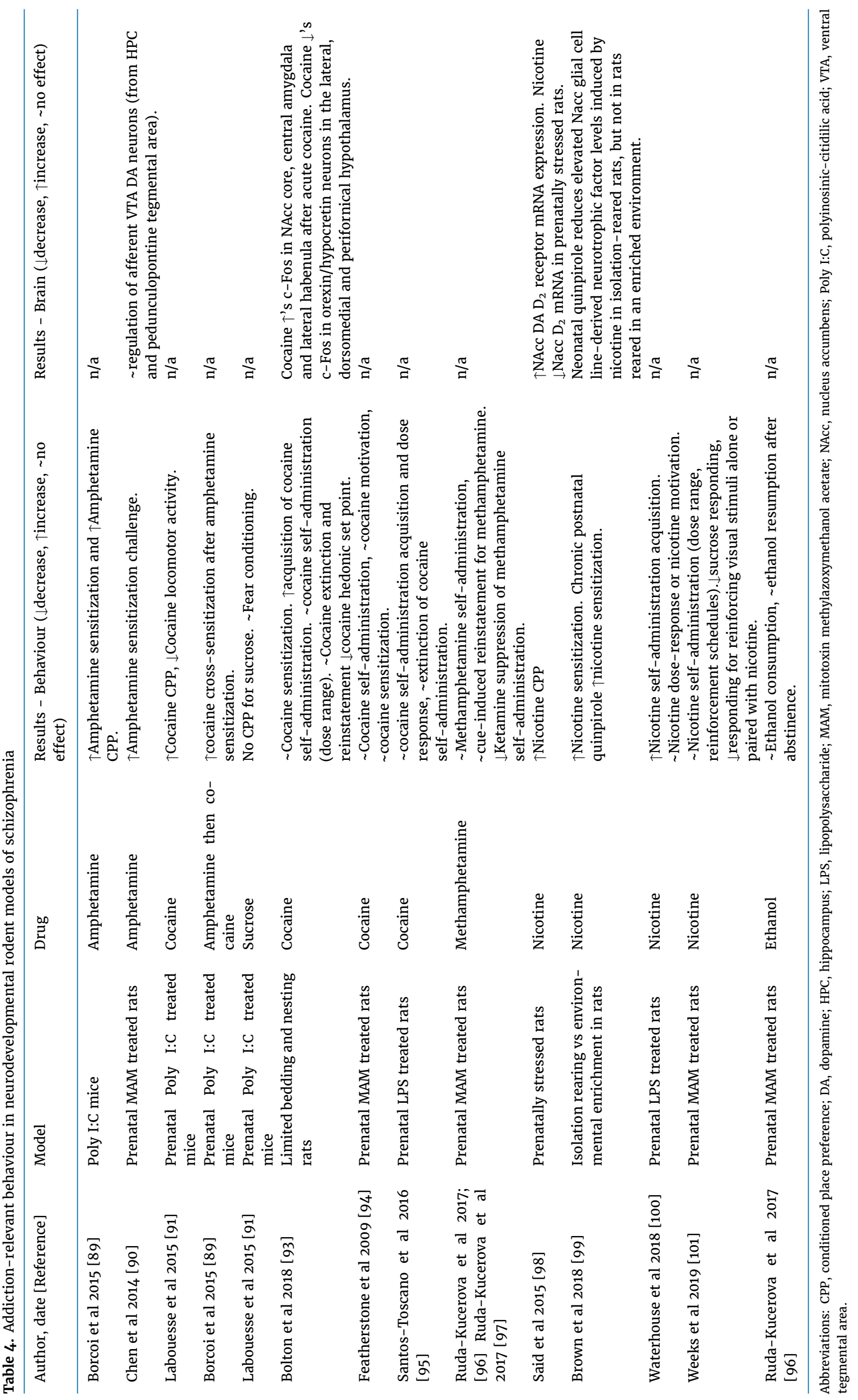


life stress (e.g. social isolation stress, chronic variable stress) can increase adult ethanol intake (e.g. [103-107], see also reviews: $[108,109])$. Elevated ethanol intake in other neurodevelopmental models may be linked to molecular changes such as decreased firing of dopaminergic VTA neurons in an LPS model [103], and may be related to altered anxiety-like states, as ethanol consumption in two-bottle free choice can be reduced by administration of anxiolytic adrenergic drugs [105]. Together, this suggests a critical role of the schizophreniarelevant model on ethanol intake and ethanol-seeking behaviour.

\subsection{Pharmacological models}

\section{Nicotine}

Only one study has examined how pharmacological models of schizophrenia respond to nicotine addiction-relevant behaviours. In models of reduced dopamine sensitivity (i.e. chronic adult amphetamine treatment) or glutamatergic dysfunction (i.e. chronic adult PCP treatment), acquisition and maintenance of intravenous nicotine self-administration is unaffected [110]. It should be noted that prior research demonstrates reduced brain stimulation reward and sucrose consumption in chronic PCP models, suggesting altered addiction-like phenotypes in this model [111, 112]. Considering this, further investigation into how pharmacological schizophrenia models respond in addiction behavioural paradigms is warranted.

\subsection{Interim Summary}

From the literature reviewed, it is clear that susceptibility to addiction-like behaviour depends on the model assessed and also the drug tested. The NVHL rat in particular exhibits elevated addiction-like behaviours to many abused drugs, including psychostimulants, nicotine, ethanol and cannabinoids. Some genetic models (e.g. Disc1 knockdown and EGF transgenic) also exhibit addiction-relevant behaviour for psychostimulants; however, other drugs of abuse have not been assessed in these models, and this is an area of critical further study. Similarly, pharmacological models of schizophrenia remain practically unexplored in their addiction-like behaviour. In non-lesion neurodevelopmental models, addiction-like phenotypes appear dependent on the drug tested, with several models showing elevated addiction-like behaviour for nicotine, but not methamphetamine or ethanol, and only one model exhibiting addiction-like behaviour for cocaine. Cannabinoids have not been assessed in non-lesion neurodevelopmental models. Addiction-like behaviours for opioids have not yet been assessed in any rodent model of schizophrenia, and this is an interesting area of future research, as recent research suggests patients with schizophrenia abuse opioids less than the general population [113]. The reasons for why some models show addiction-like phenotypes and some do not is currently unclear; however, there appear links to altered dopaminergic signalling in models which do show addiction-like phenotypes e.g. EGF overexpressing mice, prenatally stressed rats. The mechanisms driving the presence of addiction-like phenotypes in different models is an area of critical further research.

The type of research reviewed above is critical for understanding which genetic and environmental schizophrenia risk factors influence addiction susceptibility. This is particularly important for genetic risk factors e.g. DISC1, EGF, as this could facilitate future genetic counselling for patients carrying these mutations about their elevated risk for addiction, providing a personalised medicine approach. Furthermore, these studies have started to shed light on molecular changes linked to elevated addiction propensity in schizophrenia models e.g. changes in dopamine metabolism and $\mathrm{D}_{2}$ receptor function, increasing our understanding of potential mechanisms of comorbidity between these disorders. So far, the examination of mechanisms underlying addiction propensity in schizophrenia models has been limited, and has focused mostly on dopaminergic function; future research can examine other changes to other addiction-relevant neurotransmitter systems (e.g. glutamatergic, serotonergic) as well as plastic and epigenetic changes in mesocorticolimbic regions.

\section{Susceptibility of schizophrenia rodent models to effects of drugs on schizophrenia- relevant behaviour and brain function}

All preclinical studies reviewed in section 3 are summarised in Tables 5-9.

\subsection{Genetic models}

Psychostimulants - amphetamine, methamphetamine, dopamine agonists

Brain derived neurotropic factor (BDNF) is critical for hippocampal synaptic plasticity and the regulation of learning and memory [114, 115]. BDNF protein is reduced in first episode, drug naïve patients with schizophrenia $[116,117]$ and is increased after antipsychotic treatment [118]. BDNF mRNA expression is reduced in post-mortem PFC tissue from patients with schizophrenia [119], and BDNF is implicated in neural responses to psychostimulants [120]. Heterozygous BDNF mice (i.e. BDNF HET mice) exhibit prepulse inhibition deficits at baseline [121], similar to that observed in patients with schizophrenia [122].

Adult male BDNF HET mice are more sensitive to the disruptive effects of acute amphetamine on PPI compared to WT mice, but this sensitivity is not observed in female BDNF HET mice [121]. However, adult male or female BDNF HET mice do not exhibit differential sensitivity to the disruptive effects of acute apomorphine, a dopamine $\mathrm{D}_{1}$ and $\mathrm{D}_{2}$ partial agonist on PPI, suggesting drug-specific effects on PPI disruption, which may be linked to the pharmacodynamics of each dopaminergic drug (e.g. amphetamine reverses monoamine transporters, while apomorphine is a dopamine $D_{1}$ and $D_{2}$ partial agonist) [121].

In BDNF HET mice (sexes collapsed), chronic adolescent methamphetamine administration reduces cross-sensitization of locomotion to acute amphetamine, suggesting an attenuation of behaviours relevant to psychosis in methamphetaminetreated BDNF HET mice [123]. However, chronic adolescent methamphetamine administration does not alter other schizophrenia-relevant behaviours, such as social preference, social novelty, baseline prepulse inhibition or short-term memory in the Y-maze in BDNF HET males or females, compared to WT littermate controls [121, 124]. Methamphetamineinduced locomotion during the adolescent administration period is also similar between BDNF HET and WT mice, in both sexes [121]. This suggests that chronic adolescent methamphetamine in BDNF HET mice affects cross-sensitization to amphetamine, but has no effect on some schizophrenia-relevant social and cognitive behaviours.

In a mouse model of DISC 1 with the L10oP amino acid substitution in exon 2 in Disc1, acute methamphetamine-induced locomotion is not different to WT controls [125]. The effect of methamphetamine on other schizophrenia-relevant behaviours in this model has not been assessed. Considering other Disc1 models (e.g. Disc1 knockdown, Disc1 dominant neg- 
ative mutation, discussed below) exhibit greater susceptibility to addiction-like behaviour for cocaine and the cognitive impairing effects of THC, further work on this mouse model is warranted.

Together, these data suggest a limited effect of psychostimulants on schizophrenia-relevant behaviour in genetic models; however, PPI is disrupted by amphetamine and crosssensitization to methamphetamine is reduced in BDNF HET mice.

\section{Nicotine}

A schizophrenia genetic susceptibility model, the Snap-25 KO mouse, has a heterozygous deletion of the presynaptic protein SNAP-25, which is a critical component of the SNARE protein-protein complex responsible for action-potential triggered release of neurotransmitters [126]. Snap-25 KO mice do not exhibit schizophrenia-relevant behaviours in adolescence at baseline e.g. locomotor hyperactivity, social withdrawal; however, there is a gene $*$ in utero interaction, whereby locomotor hyperactivity and social withdrawal in adolescence are evident following prenatal nicotine exposure in Snap-25 KO mice, but not WT controls [126]. Prenatal nicotine treatment in Snap$25 \mathrm{KO}$ mice also impairs striatal $\mathrm{D}_{2}$ receptor dependent longterm depression (LTD) and reduces striatal $\mathrm{D}_{2}$ receptor affinity, but leaves striatal $\mathrm{CB}_{1}$ receptor regulated plasticity intact, compared to Snap-25 KO mice without prenatal nicotine exposure [126]. This suggests that intact expression and function of Snap-25 may be protective against the effects of prenatal nicotine on schizophrenia-like behaviour, as well as striatal $\mathrm{D}_{2}$ receptor expression and function.

SNPs in the human CHRNA5 gene, which encodes the $\alpha 5$ nicotinic acetylcholine (nACh) receptor subunit, increases risk for both smoking and schizophrenia [127]. Mice which express a human $\alpha 5$ SNP (i.e. $\alpha 5$-SNP-expressing mice) show impaired social behaviour and sensorimotor gating, as well as lower activity of vasoactive intestinal polypeptide (VIP) interneurons, which results in increased somatostatin interneuron inhibitory drive over layer II/III pyramidal neurons [128]. Importantly, the decreased activity observed in $\alpha 5$-SNPexpressing mice resembles the hypofrontality observed in patients with schizophrenia and addiction [128]. Chronic nicotine administration reverses this hypofrontality, supporting the self-medication hypothesis when alterations to nACh subunit $\alpha 5$ are present [128].

G72 is a gene from schizophrenia-associated genetic region SCZD7 on chromosome 13q32-q33, and elevated G72 transcript levels are observed in forebrain structures in post-mortem tissue of patients with schizophrenia [129]. In transgenic mice overexpressing $\mathrm{G72}$, chronic adult nicotine administration reverses impairments in social memory, working memory and PPI, compared to vehicle $G_{72}$ transgenic mice [130]. Chronic nicotine also reverses the upregulation of oxytocin receptor binding in the central amygdala observed in vehicle treated $G_{72}$ transgenic mice, which may relate to improvements in social memory in nicotine-treated G72 transgenic mice [131]. The G72 mutation is also protective against operant associative memory deficits caused by chronic nicotine, but long-term spatial learning in the Morris Water Maze is worsened by chronic nicotine treatment in $G_{72}$ mice [130], suggesting domain-specific effects of chronic nicotine in this model.

Reelin is a large extracellular matrix protein critically involved in brain development and neural plasticity. Reelin deficits have been observed in schizophrenia [132], and heterozygous reeler mice exhibit hyperlocomotion, PPI and cognitive deficits, and perseverative behaviour [133-135], as well as a loss of Purkinje cells of the cerebellum, which is also observed in patients with schizophrenia $[136,137]$. In adolescent heterozygous reeler mice, subchronic (6 day) nicotine free choice drinking ameliorates hyperlocomotion, perseverative behaviour and cognitive impairment $[138,139]$. Furthermore, in heterozygous reeler mice, subchronic nicotine restores mRNA levels of reelin and GAD67 in the cortex, hippocampus, striatum and cerebellum to WT-like levels $[138,139]$. Together, this suggests protective effects of subchronic nicotine in the heterozygous reeler mouse.

Neuregulin 1 is a well-established risk gene for schizophrenia, involved in processes such as axon guidance, synapse formation and synaptic plasticity, as well as excitatory glutamatergic and inhibitory GABAergic transmission [140, 141]. Alternative splicing leads to $>30$ NRG1 isoforms, and several mouse models have been developed to study altered Nrg1 function with reference to schizophrenia. Type III Neuregulin 1 heterozygous knockout (Type III Nrg1 HET) mice exhibit social interaction impairment and PPI deficits at baseline. Type III Nrg1 HET mice are also less sensitive to the effects of acute nicotine on theta-burst stimulation elicited long-term potentiation (LTP) in cortical-basolateral amygdala (BLA) synapses, such that in WT mice, nicotine reduces the threshold for the activation of LTP in cortical-BLA synapses, but this effect is absent in Type III Nrg1 mutant mice [142]. This effect in Type III Nrg1 HET animals is dependent on $\alpha 7$ nicotinic receptors [142]. Interestingly, chronic (6 weeks) nicotine consumption in drinking water improves PPI in Type III Nrg1 transgenic mice [143]. Considering that the ameliorative effects of nicotine on PPI deficits involve $\alpha 7$ nicotinic receptors [144], and type III NRG1 backsignalling regulates $\alpha 7$ nicotinic receptor surface expression [145], it is possible that chronic nicotine treatment in Type III Nrg1 mutant mice may restore $\alpha 7$ nicotinic receptor surface expression in the cortex and BLA to WT levels.

Together, these studies indicate that sensitivity to the effects of nicotine on schizophrenia-relevant behaviour and brain function depends on the model used, with most models showing protective or ameliorative effects of nicotine (e.g. G72 transgenic, heterozygous reeler, Type III Nrg1 transgenic mice), but some models showing development of schizophreniarelevant behaviours only following nicotine administration (e.g. Snap-25 KO mice). Considering several models show ameliorative effects of nicotine, this provides support for the self-medication hypothesis, whereby nicotine improves schizophrenia-relevant behaviour and brain function, which may help explain high usage rates in patients. Nicotine administration is accompanied by a range of neural changes, including reduced striatal LTD, increased oxytocin receptor binding in the central amygdala, increased reelin and GAD67 mRNA expression in the hippocampus, striatum, cortex and cerebellum, and a reduced threshold for LTP activation in cortical-BLA synapses, The timing of nicotine administration (e.g. neonatal $v s$ adolescence $v s$ adulthood) may impact on potential ameliorative effects of nicotine, but this has not yet been investigated.

\section{NMDA antagonists}

A novel Type III Nrg1 overexpression mouse (i.e. Nrg1 III $t g)$, which models the elevated Type III NRG1 mRNA detected in postmortem dorsolateral PFC tissue of patients with schizophrenia [146], exhibits sex-specific cognitive, social and prepulse inhibition impairment, but no changes to locomotor activity in either sex [147]. However, acute hyperlocomotor activity in response to the NMDA antagonist MK- 801 is blunted in adult female $\mathrm{Nrg1}$ III $\mathrm{tg}$ mice [147]. Interestingly, this effect is not observed in adult male Nrg1 III $t g$ mice, where hyperlocomotion following MK-801 is similar to WT mice [148]. This may suggest a reduced number of available NMDA receptors in Nrg1 III $t g$ female mice, in alignment with the NMDA receptor hypofunction theory of schizophrenia [56]. However, in BDNF HET mice, acute MK-801 does not differentially affect prepulse inhibition in male or female BDNF HETs compared to 


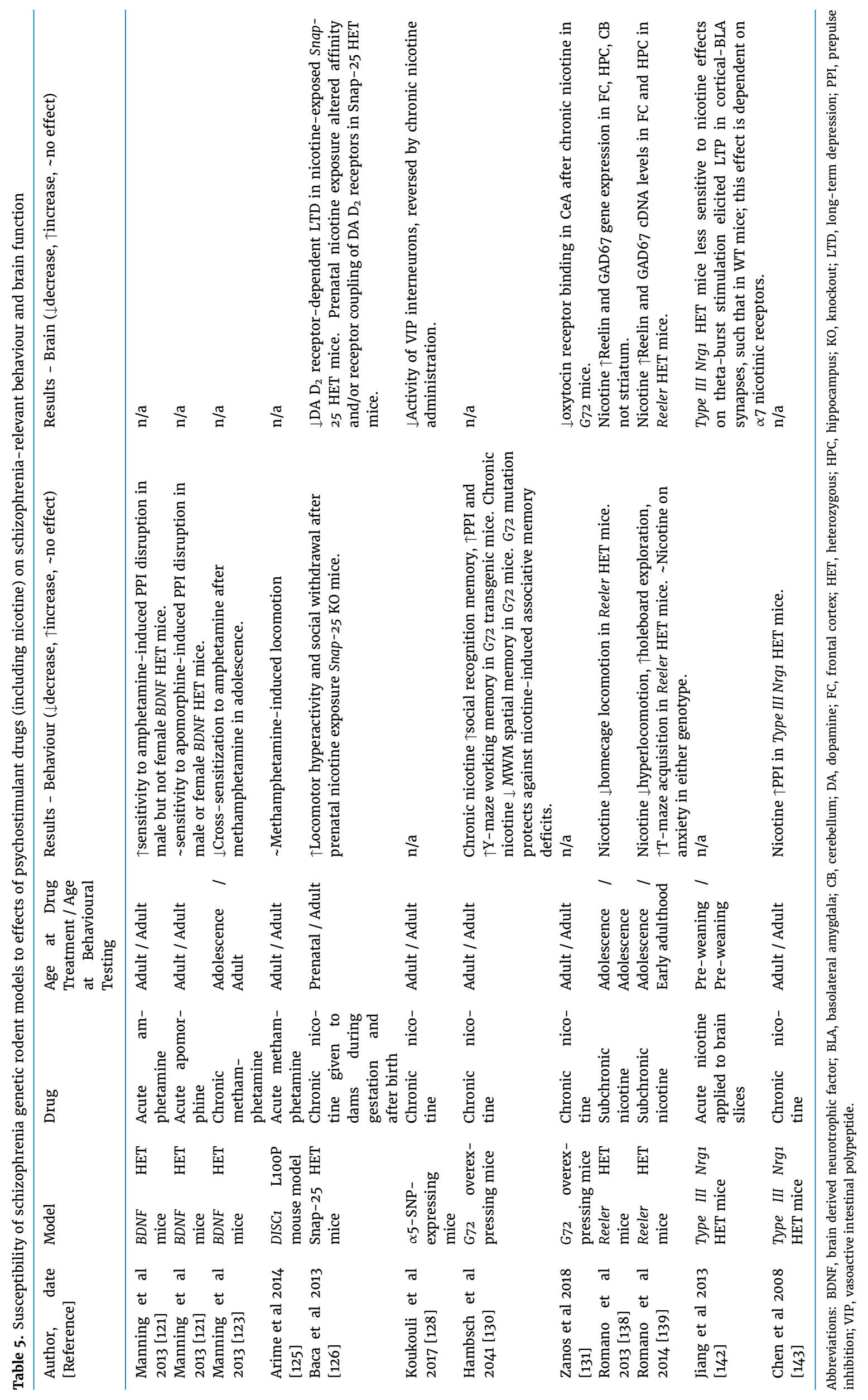


WT mice [121], indicating model-specific effects of MK-801 on schizophrenia-relevant behaviour.

\section{Cannabinoids: Cannabidiol}

Spontaneously hypertensive rats (SHR) are a model of schizophrenia, exhibiting behaviours including hyperlocomotion, sensorimotor gating deficits, associative memory impairment and reduced social behaviour [149]. Cannabidiol (CBD) is a non-intoxicating cannabis plant compound which is a weak $C_{1}$ receptor negative allosteric modulator [150], and is being investigated as a potential anti-psychotic [151] In SHR, acute CBD treatment does not reverse hyperlocomotion and social withdrawal [152]. However, chronic low dose (i.e. $0.5-5 \mathrm{mg} / \mathrm{kg}$ ) CBD treatment during adolescence dosedependently reverses locomotor hyperactivity, sensorimotor gating deficits and fear-associated cognitive impairment in SHR [153]. Chronic adolescent CBD treatment also increases the ratio of 5-HIAA/serotonin tissue levels in the PFC in adulthood in both SHR and controls, but CBD has no effect on serotonin levels in the dorsal striatum or BDNF levels in the PFC or dorsal striatum [153], suggesting that CBD ameliorates schizophreniarelevant behaviours in SHR by a different mechanism (e.g. increasing anandamide levels [154]).

Similarly, in a different Neuregulin 1 mouse model of schizophrenia (i.e. the Neuregulin 1 transmembrane domain heterozygous mouse, $\mathrm{Nrg} 1 \mathrm{TM}$ HET), which exhibits hyperlocomotion, impaired social behaviour and PPI deficits at baseline $[155,156]$, acute treatment with higher doses of CBD (i.e. 50 $100 \mathrm{mg} / \mathrm{kg}$ ) reverses PPI deficits, compared to vehicle treated Nrg1 mutants [157]. Also, chronic treatment in this dose range increases social behaviour and increases GABA-A receptor binding in the granular retrosplenial cortex in adult Nrg1 TM HET mice [157]. However, chronic CBD does not reverse locomotor hyperactivity, sensorimotor gating deficits or reduced $5-\mathrm{HT}_{2 \mathrm{~A}}$ receptor binding density in the substantia nigra of these mice [157]. While this indicates CBD can have ameliorative effects on schizophrenia-relevant behaviours, it also shows that the effects of CBD can depend on the model used, the age targeted (e.g. adolescence vs adulthood) and the dose used.

\section{Cannabinoids: $\Delta^{9}$-Tetrahydrocannabinol}

Several models of genetic risk for schizophrenia are more sensitive to behavioural and neural effects of THC. The dominant negative Disc1 (DN-Disc1) mutant mouse is more susceptible to the effects of adolescent THC treatment than WT controls [158]. Chronic THC in adolescence increases anxiolytic behaviour and impairs short-term memory in DN-Disc1 mutant mice, where these effects are not apparent in WT controls [158]. The cognitive impairment induced by THC in DN-Disc1 mice may be linked to hippocampal $\mathrm{CB}_{1}$ receptor and BDNF levels, as chronic THC selectively increases hippocampal $\mathrm{CB}_{1}$ receptor and BDNF protein levels in WT mice but not in DN-Disc1 mice [158]. Interestingly, overexpression of hippocampal BDNF in DN-Disc1 mice prevents THC-induced cognitive impairment in these mice, suggesting that BDNF upregulation may be a homeostatic response designed to maintain proper cognitive function following exogenous insult [158].

In the Nrg1 TM HET model of genetic risk for schizophrenia, Nrg1 TM HET males are more sensitive to the locomotor suppressing and PPI enhancing effects of acute THC than are THCtreated WT controls [159]. Female Nrg1 TM HET mice do not exhibit this elevated sensitivity to THC in terms of locomotion and PPI, and are even less susceptible than WTs to the supressing effects of THC on some social behaviours [160]. The Nrg1 gene mutation assessed also impacts on susceptibility to THC, as male mice from a different Nrg1 mutant model, i.e. Nrg1 III $t g$ mice do not exhibit altered THC-induced locomotion, social behaviour or prepulse inhibition, compared to THC-treated WT controls [161].

In adolescence, the Nrg1 TM HET mutation protects against inhibiting effects of chronic THC on investigative social behaviours in male mice [162]. However, adolescent Nrg1 TM HET mice continue to demonstrate locomotor suppression after 2 days washout from THC where WTs do not, suggesting increased susceptibility to locomotor, but not social effects of THC in adolescent Nrg1 TM mutants [162].

There are complex effects of chronic adolescent THC treatment on receptor expression across the brain in Nrg1 TM HET mice. Chronic adolescent THC increases $\mathrm{CB}_{1}$ receptor binding in the substantia nigra in Nrg1 but not WT mice [162]. Considering the role of $\mathrm{CB}_{1}$ receptors in controlling dopamine release in the basal ganglia direct pathway, this elevation in $\mathrm{CB}_{1}$ receptor binding may reflect continued suppression of locomotion following chronic THC in adolescent Nrg1 mutant mice [162]. In addition, the elevation in NMDA receptor binding in the hippocampus, auditory cortex and cingulate cortex in THC-treated adolescent Nrg1 TM HET but not WT mice may also contribute to the continued locomotor suppression in Nrg1 mutants, as NMDA receptor antagonism induces hyperlocomotion, and increased NMDA receptor binding may reflect reduced locomotion ([162] see also [163]). Finally, adolescent THC treatment increases $5-\mathrm{HT}_{2 A}$ receptor binding in the agranular insular cortex in Nrg1 mutants, whereas in WTs, THC treatment reduces $5-\mathrm{HT}_{2 A}$ binding in the agranular insular cortex, ventral pallidum and cingulate cortex, and increases $5-\mathrm{HT}_{2 A}$ binding in the caudate-putamen [162]. In patients with schizophrenia, reduced $5-\mathrm{HT}_{2 A} \mathrm{R}$ density is observed post-mortem in prefrontal and other cortical regions $[164,165]$, and may relate to social withdrawal and social anxiety observed in patients. The elevation of $5-\mathrm{HT}_{2 \mathrm{~A}}$ receptor binding in $\mathrm{Nrg} 1$ mutants may reflect the protective effect of the $\mathrm{Nrg}_{1}$ genotype on the social behaviour-suppressing effects of THC [162].

Using a proteomics approach, Spencer and colleagues [163] demonstrated that adolescent Nrg1 TM mutants chronically treated with THC show an altered profile of proteins which affect synapse formation and dendritic spine dynamics [163]. Chronic adolescent THC in Nrg1 mutants induces changes in several proteins involved in intracellular trafficking and stabilization of NMDA receptors at the synapse (e.g. FLOT1, APOA1, GPSM2) [163]. Interestingly, THC treatment caused proteomic changes in WT mice suggestive of greater oxidative stress and neurodegeneration than in $\mathrm{Nrg} 1$ mutant mice, again suggesting a degree of protection against some effects of THC in Nrg1 TM HET mice [163]. These findings may help to explain the altered behavioural responses of Nrg1 TM HET mice to cannabinoid treatment.

Clinical data indicates a complex relationship between cannabis use and schizophrenia susceptibility between the sexes [166-169]. It is possible risk genes modulate this relationship, e.g. BDNF Val66Met genotype when coupled with cannabis abuse modulates risk for psychosis onset in females, but not males [167]. The preclinical data presented above suggests complex interactions between cannabinoid treatment, schizophrenia genetic susceptibility and sex, where cannabinoids can both protect against and worsen schizophrenia-like behaviour. Further investigation into sex differences in these cannabis-gene interactions is warranted.

\subsection{Lesion models}

\section{Psychostimulants: amphetamine}

In NVHL rats, acute amphetamine-induced locomotion is enhanced compared to sham controls [72, 77, 85]. The effects of NVHL on amphetamine-induced locomotion may be agedependent, as rats in early adolescence (i.e. PND 35) do not 


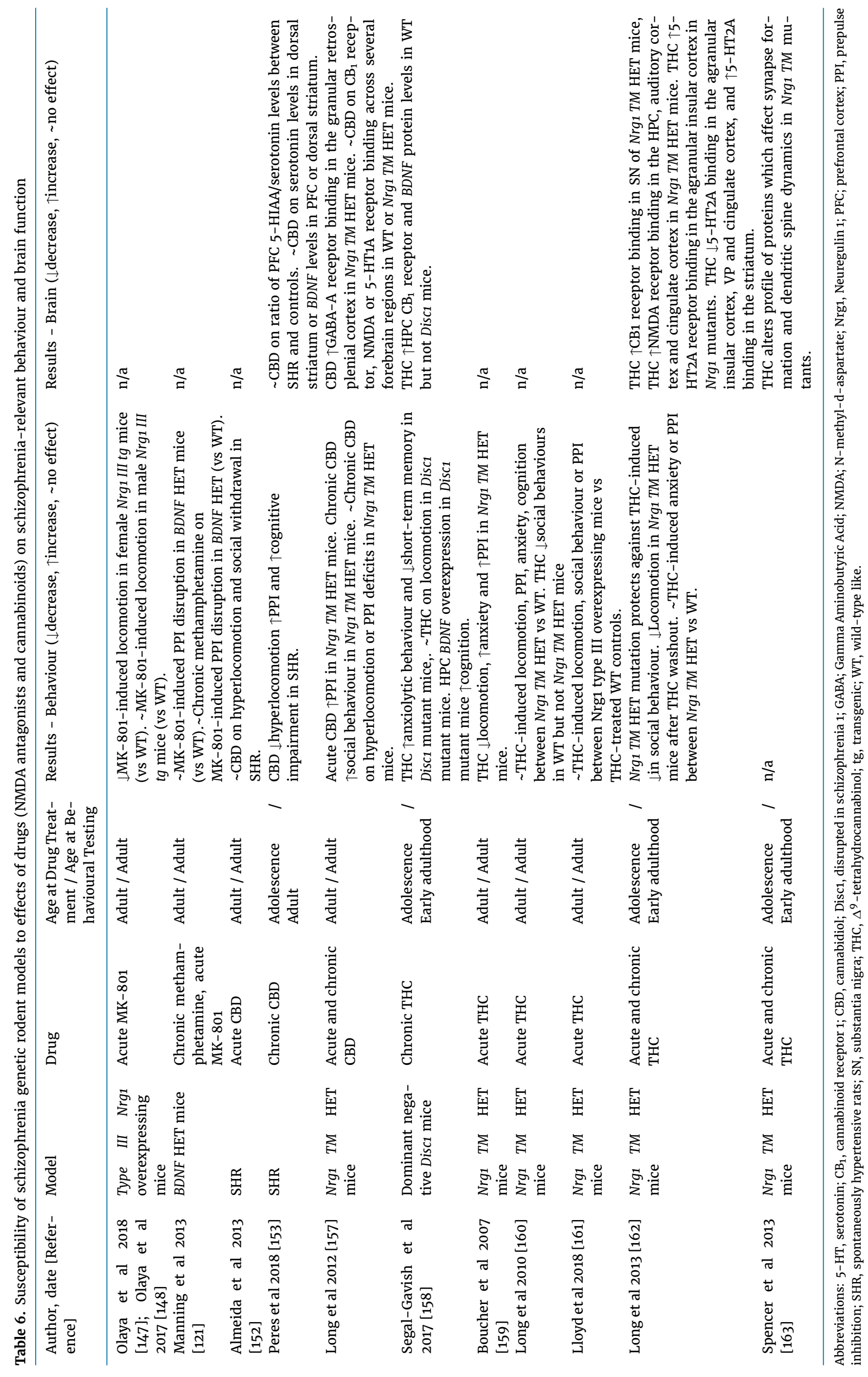


exhibit altered acute amphetamine-induced locomotion compared to controls, where NVHL rats in late adolescence/young adulthood (PND 56) do [85]. This indicate an age * drug interaction in NVHL rats, potentially reflecting late adolescent developmental changes in the mesolimbic pathway, relevant to the development of schizophrenia at this age.

\section{Nicotine}

NVHL rats exhibit deficits in learning and memory in the radial arm maze $[72,74,170]$. Unlike some genetic models (e.g. G72 transgenic mice, reeler mice, Type III Nrg1 HET mice, detailed above), chronic nicotine treatment in adolescence or adulthood does not reverse cognitive impairment in the radial arm maze in NVHL rats $[72,74,170]$. Chronic adolescent or adult nicotine treatment also does not differentially affect nACh receptor binding in $\mathrm{MPFC}$ or ventral striatum in NVHL rats compared to sham controls [170]. These studies suggest limited effects of nicotine on learning and memory, as well as nACh receptor binding in NVHL rats. The effects of nicotine on other schizophrenia-relevant domains e.g. hyperlocomotion, social behaviour, sensorimotor gating are yet to be examined.

\subsection{Non-lesion neurodevelopmental models}

\section{Psychostimulants: amphetamine}

Offspring of maternal LPS-treated rats are more sensitive to amphetamine in early adulthood, displaying a reduced breakpoint for a food reinforcer under amphetamine treatment, and greater amphetamine-induced locomotion than controls [171]. However, these effects depend on the gestational day (G12 vs G16) at which LPS is administered, suggesting age-specific effects of LPS on brain development and subsequent drug reward susceptibility [171]. Embryonic midbrain dopaminergic neurons are reduced $48 \mathrm{hr}$ after LPS treatment at E16 but this recovers by adolescence, while midbrain dopaminergic neurons are unaffected by LPS treatment at E12 [171]. This suggests altered dopaminergic function following maternal LPS treatment, which is protocol dependent and shows a degree of recovery with time. Considering the recovery of dopaminergic midbrain neurons following LPS treatment, it is possible sensitivity to amphetamine in LPS rats is mediated by dopaminergic neurons in a different brain region e.g. forebrain regions such as the dorsal and ventral striatum.

\section{Nicotine}

Cognitive deficits in rats prenatally treated with LPS are ameliorated by chronic nicotine self-administration, compared to LPS rats which self-administer saline [100]. This may indicate a restoration of deficits in nicotinergic $\alpha 7$ and $\alpha 4 \beta 2$ receptor subtype function in LPS treated rats; however, this has not been assessed experimentally [100]. The effects of acute or chronic nicotine in neurodevelopmental models (e.g. MAM, Poly I:C, LBN) have not yet been assessed. However, considering interactions between the immune system and nicotine $[172,173]$, this is an interesting area of future research.

\section{Cannabinoids: CBD, WIN, fatty acid amide hydrolase inhibitors}

Osborne and colleagues examined the effects of CBD in a rat Poly I:C model of maternal infection, which exhibit cognitive deficits and social interaction impairment [174]. In males, chronic CBD treatment in early adulthood rescued deficits in short term working memory in the novel object recognition test and rewarded $\mathrm{t}$-maze, as well as social interaction deficits in Poly I:C rats, with no effects of CBD in non-Poly I:C treated rats [174]. Chronic CBD treatment in early adulthood attenuated Poly $\mathrm{I}: \mathrm{C}$-induced deficits in $\mathrm{CB}_{1}$ receptor binding in the PFC as well as GAD67 binding in the hippocampus [175]. CBD also increased protein levels of the interneuron marker parvalbumin in the hippocampus, irrespective of maternal infection, but did not affect NMDA or GABA-A receptor binding or protein levels of fatty acid amide hydrolase (FAAH), the enzyme which degrades anandamide, in the PFC or hippocampus. Overall, these findings suggest that in male rats, CBD may reverse schizophrenia-relevant negative and cognitive behaviours by restoring cannabinoid/GABAergic signalling deficits.

Similarly, in female Poly I:C rats, chronic CBD in early adulthood attenuates recognition memory and social interaction deficits, and reverses the Poly I:C induced reduction in NMDA receptor binding in the PFC [176]. Poly I:C also increases GAD67 and parvalbumin interneuron protein levels in the hippocampus [176]. Interestingly, CBD administration control rats (i.e. no Poly I:C treatment) reduces social interaction, as well as cannabinoid $\mathrm{CB}_{1}$ receptor and NMDA receptor binding in the $\mathrm{PFC}$, suggesting that $\mathrm{CBD}$ administration to healthy rats may have negative consequences on social behaviour and brain maturation in adulthood [176]. Together, this supports the antipsychotic potential of CBD for the treatment of cognitive and negative symptoms in schizophrenia but not healthy controls (review: [151]), and suggests CBD could be acting by reversing $P F C \mathrm{CB}_{1}$ and NMDA receptor dysfunction and increasing GABA receptor function in the hippocampus, in a sex-specific manner.

In another model of maternal infection, the MAM model, chronic adolescent treatment with the $\mathrm{CB}_{1}$ receptor agonist WIN prevents amphetamine-induced hyperlocomotion, but does not reverse deficits in a set-shifting task in MAM treated rats [177]. Interestingly, the effect of WIN on amphetamineinduced locomotion in MAM rats occurs in the absence of changes to dopaminergic neuron firing in the VTA [177], although cell activity in other brain regions relevant to locomotor sensitization (e.g. NAcc) were not assessed in this study. These findings are surprising as $\mathrm{CB}_{1}$ receptor agonists often exacerbate schizophrenia symptoms [178]. The authors suggest that pubertal exposure to WIN may have changed the expression of components of the endocannabinoid system in brain structures related to motivation and motor control, thus limiting amphetamine-induced hyperlocomotion in MAM rats [177].

In a novel rodent model of schizophrenia susceptibility, the F2 methylazoxymethanol acetate (F2 MAM) rat, where only a proportion ( $40 \%$ ) of rats display a schizophrenia-relevant phenotype (i.e. hyperdopaminergic phenotype characterized by increased dopamine neuron activity in the VTA), subchronic adolescent WIN treatment increases the proportion of F2 MAM rats with a schizophrenia-like phenotype (i.e. hyperdopaminergia) in early adulthood (i.e. from $36 \%$ to $71 \%$ ), with no corresponding increase in schizophrenia-like phenotypes in WT controls [179]. Adolescent WIN treatment also increases sensitivity to acute amphetamine locomotor activity in early adulthood in F2 MAM rats, compared to WT controls [179]. Similarly, increasing endogenous cannabinoid signalling via the FAAH inhibitor URB597 also increases the proportion of F2 MAM rats with a schizophrenia-like phenotype in early adulthood (i.e. from $40 \%$ to $80 \%$ ), but unlike WIN treatment, has no effect on amphetamine sensitivity [179]. This data mirrors clinical observations of increased risk for developing schizophrenia following cannabis abuse in individuals with genetic risk for the disorder [180-182], and will facilitate further investigation of the molecular and genetic mechanisms driving this susceptibility.

\subsection{Pharmacological models}

Psychostimulants: amphetamine

In a rat model of dopamine supersensitivity (i.e. withdrawal from chronic haloperidol), amphetamine treatment increases 


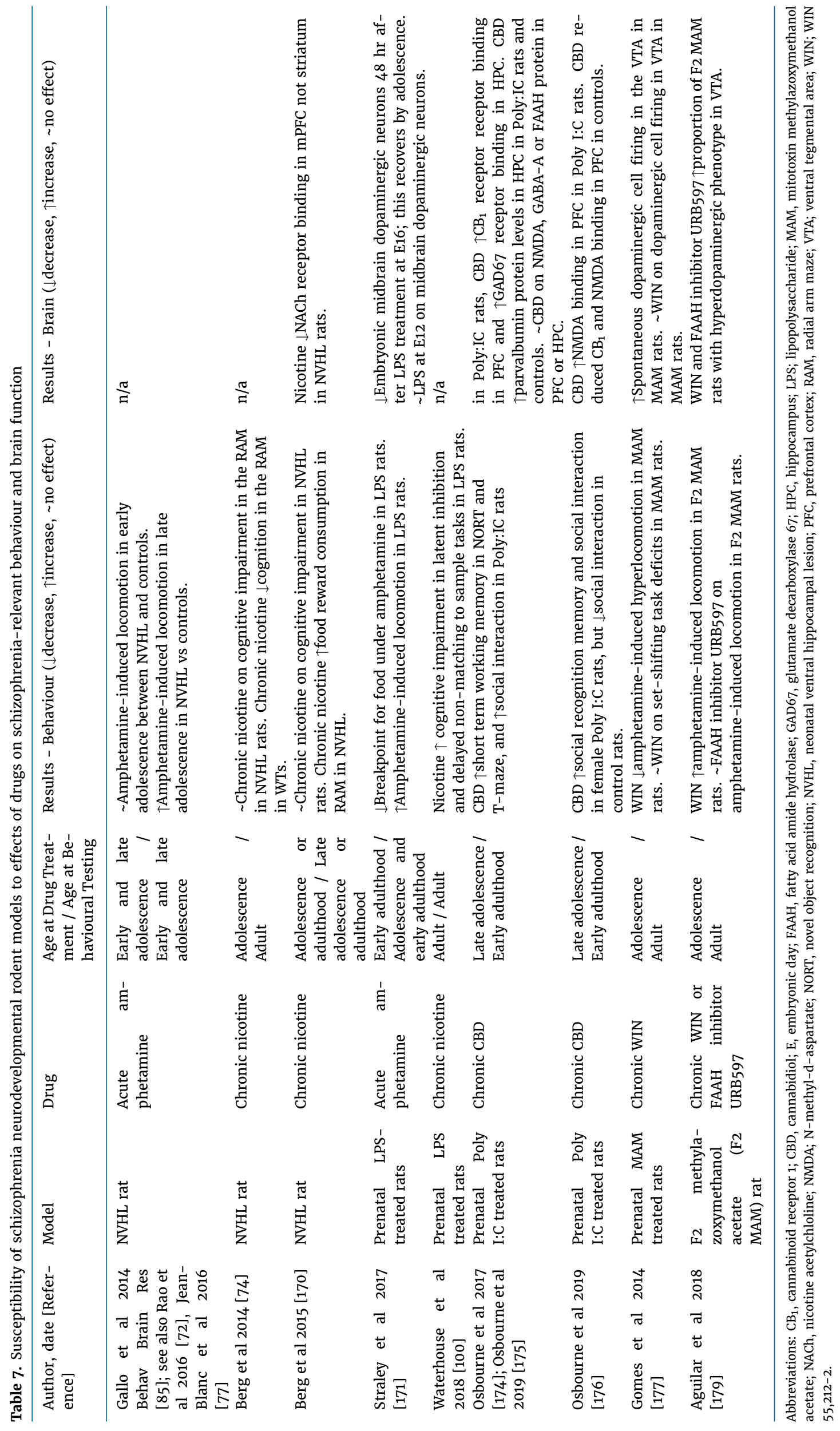


the pursuit of food-based reward cues more vigorously in dopamine supersensitive rats than control rats [183-185]. This effect does not appear mediated by NAcc function, as intraNAcc amphetamine injections or NAcc inhibition via GABA receptor agonists does not alter pursuit of food-based cues [185] Baseline food-seeking, however, is unaltered by dopamine supersensitivity [183]. Amphetamine-induced locomotion as well as c-fos mRNA in the caudate putamen is also elevated following chronic haloperidol, compared to vehicle-treated controls [184]. While further research needs to be conducted in this field, these results suggest altered reward could be present in schizophrenia-relevant pharmacological models of altered dopamine function.

\section{Nicotine}

Information processing, in particular $40 \mathrm{~Hz}$ steady-state auditory evoked responses, is deficient in patients with schizophrenia [186], and assessment of auditory evoked responses in rodents can be used to model this in the laboratory. Acute MK801 impairs auditory-evoked neural responses in anaesthetised rats [187], and MK-801 also exacerbates psychotic symptoms in patients with schizophrenia [188]. Interestingly, MK-801 induced impairment in auditory-evoked responses is ameliorated by acute nicotine administration [187]. Similarly, acute MK-801-induced memory impairments in mice are improved by acute nicotine administration [189], while chronic nicotine reverses heightened impulsivity in a mouse chronic PCP model [190]. Finally, systemic and intra-orbitofrontal cortex administration of nicotine or the nAChR agonist ABT-418 dose-dependently ameliorates chronic ketamine-induced impairments in a multisensory integration task, and this effect is blocked by GABA-A receptor antagonism [191]. These effects appear dependent on parvalbumin interneurons in the orbitofrontal cortex, as silencing parvalbumin interneurons impairs multisensory integration task performance, and this is reversed by ABT-418 administration [191]. Collectively, this suggests acute and chronic nicotine can improve cognitive impairment in an MK-801 schizophrenia rodent model, an effect which may depend on parvalbumin interneuron function in the PFC.

\section{Cannabinoids: THC, WIN, FAAH inhibitors}

PCP treatment, either neonatally or in adulthood, increases behavioural and brain responses to cannabinoids. A single neonatal PCP administration at G7 increases vulnerability to chronic adolescent THC-induced deficits in memory performance and sensorimotor gating [192]. Neonatal PCP also induces hyperlocomotion in adult mice which are chronically treated with THC (n.b. mice were tested for locomotor activity after at least 27 days of THC treatment, reducing the sedative effects of THC [192]). These behavioural effects are associated with reduced NMDA NR1 receptor protein in the cortex, reflecting a reduction in glutamatergic signalling which is hypothesised to contribute to schizophrenia pathophysiology [192].

When rats are treated subchronically in adulthood with PCP, this increases $\mathrm{mPFC}$ firing rates in response to the FAAH inhibitor URB597, suggesting increased susceptibility to elevated levels of endocannabinoids in PCP-treated rats compared to vehicle-treated controls [193]. Conversely, PCP-treated animals are unaffected by THC, where THC treatment decreases $\mathrm{mPFC}$ firing rates in saline treated animals [193]. Subchronic PCP treatment does not modulate firing rates in response to URB597 or THC in the ventral hippocampus, suggesting an mPFC-specific effect [193]. Considering neural oscillations are disrupted in schizophrenia, and cannabinoids can acutely decrease the power of neural oscillations [194], these findings can start to shed light on how cannabinoids affect mPFC neural firing in schizophrenia.
Interestingly, cannabinoids may have protective effects when administered prior to PCP. In rats which either selfadminister or are treated chronically with the $\mathrm{CB}_{1}$ receptor agonist WIN, the sensitized locomotor response to a PCP challenge is decreased in WIN-treated animals, compared to vehicle controls [195]. WIN self-administration also increases exploratory behaviour (i.e. rearing) and reduces anxiety-like behaviour in an open field arena in response to acute PCP administration [195]. Interestingly, PCP-induced social withdrawal and reduced anandamide levels in the PFC and amygdala can be reversed by elevating endogenous cannabinoids via the FAAH inhibitor URB597, or by increasing cannabinoid signalling via the cannabinoid agonist $\mathrm{CP} 55,940$ [196, 197]. This suggests PCP-induced social withdrawal and sensitized locomotor activity may result from deficient endocannabinoid transmission [196].

In a rat model selectively bred following social isolation housing and ketamine treatment in adolescence, WIN-induced G-protein activation is reduced in the cerebellum, cortex and in subcortical regions [198]. $\mathrm{CB}_{1}$ receptor binding is also reduced in the cerebellum, cortex and subcortical regions in this rat model of schizophrenia, compared to controls [198]. These reductions in cannabinoid receptor binding and function correspond with similar endocannabinoid system changes and elevated susceptibility to cannabinoids in patients with schizophrenia (e.g. [199-201]).

Together, these results suggest cannabinoids generally worsen positive-like and cognitive behaviours, and cause altered receptor binding (e.g. cannabinoid, glutamatergic) and mPFC firing in pharmacological models of schizophrenia. This reflects clinical data, which demonstrates cannabis use can worsen symptoms in patients with schizophrenia, and in first episode patients, recent cannabis use is associated with decreased grey matter volume in the posterior cingulate cortex (review: [202]). Interestingly, in rodent models, the timing of cannabinoid administration can modulate this effect; cannabinoid administration prior to PCP treatment appears protective against schizophrenia-relevant behaviours.

\subsection{Interim Summary}

In Section 3, we summarised how abused drugs can exacerbate or alleviate schizophrenia-relevant behaviours in several rodent models of schizophrenia. Interestingly, there are some fairly consistent findings across models and drug classes. Nicotine, for example, often ameliorates schizophrenia-relevant behaviours, as observed in most genetic models, one neurodevelopmental model and one pharmacological model. Cannabinoids have bidirectional effects on schizophrenia-relevant behaviours, with $\mathrm{CB}_{1}$ agonists (e.g. THC, WIN) mostly worsening these behaviours in genetic, neurodevelopmental and pharmacological models (although there are some exceptions), and CBD ameliorating schizophrenia-like behaviours in genetic and neurodevelopmental models. There is limited data available on the effects of psychostimulants on schizophreniarelevant behaviour; however, lesion and pharmacological models show elevated sensitivity to psychostimulants, which can be age-dependent. The effects of nicotine, cannabinoids and psychostimulants mirrors what is observed in clinical literature, e.g. nicotine improves attention and processing speed in individuals with schizophrenia $[203,204]$, cannabis worsens schizophrenia symptoms and clinical prognosis [205], CBD has antipsychotic-like effects [206], and there is recent evidence of increased susceptibility to effects of amphetamine on sensorimotor gating in schizophrenia [207]. Importantly, this provides predictive validity to these models, and facilitates the use of these models to better understand brain changes associ- 


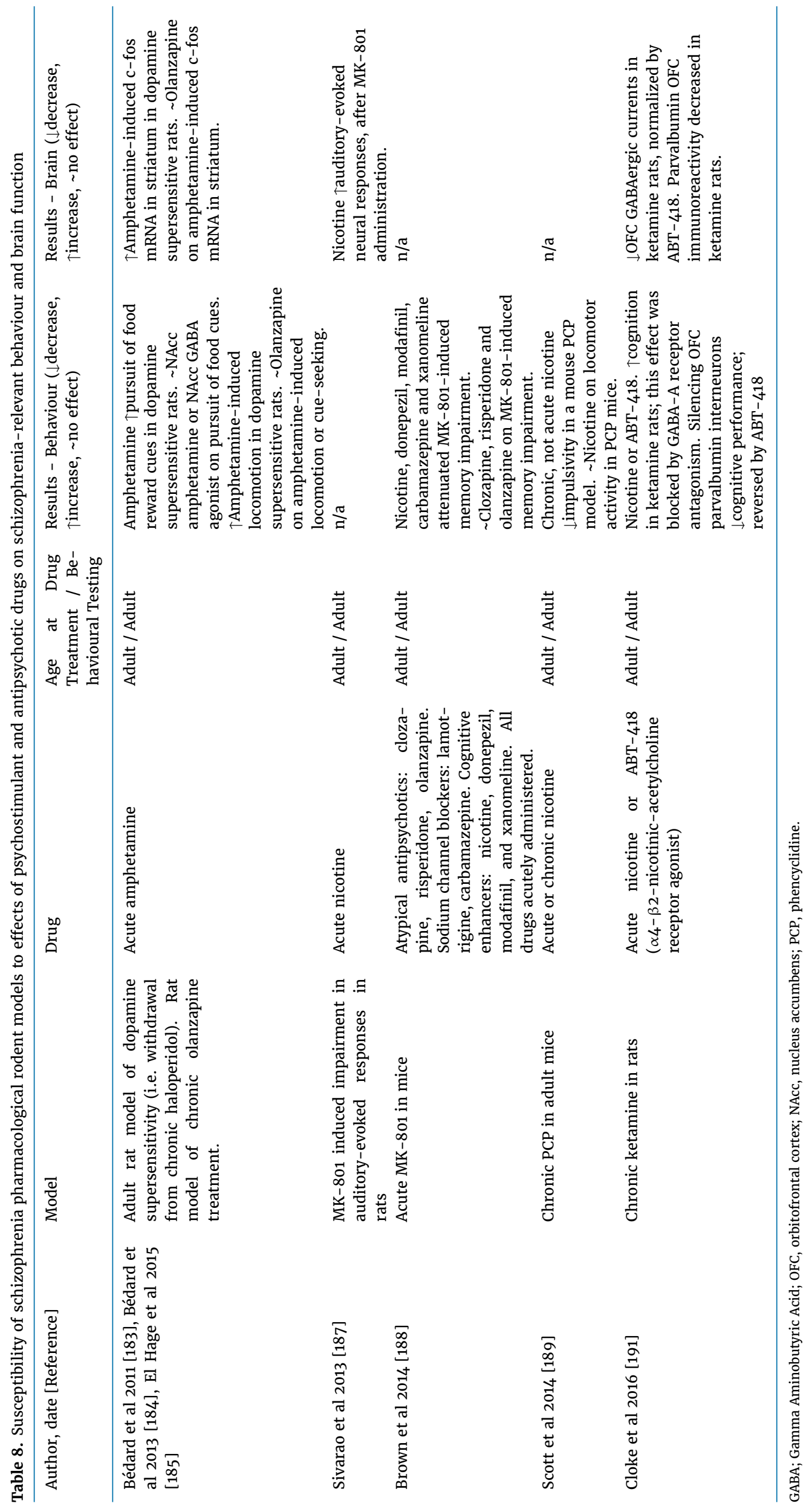




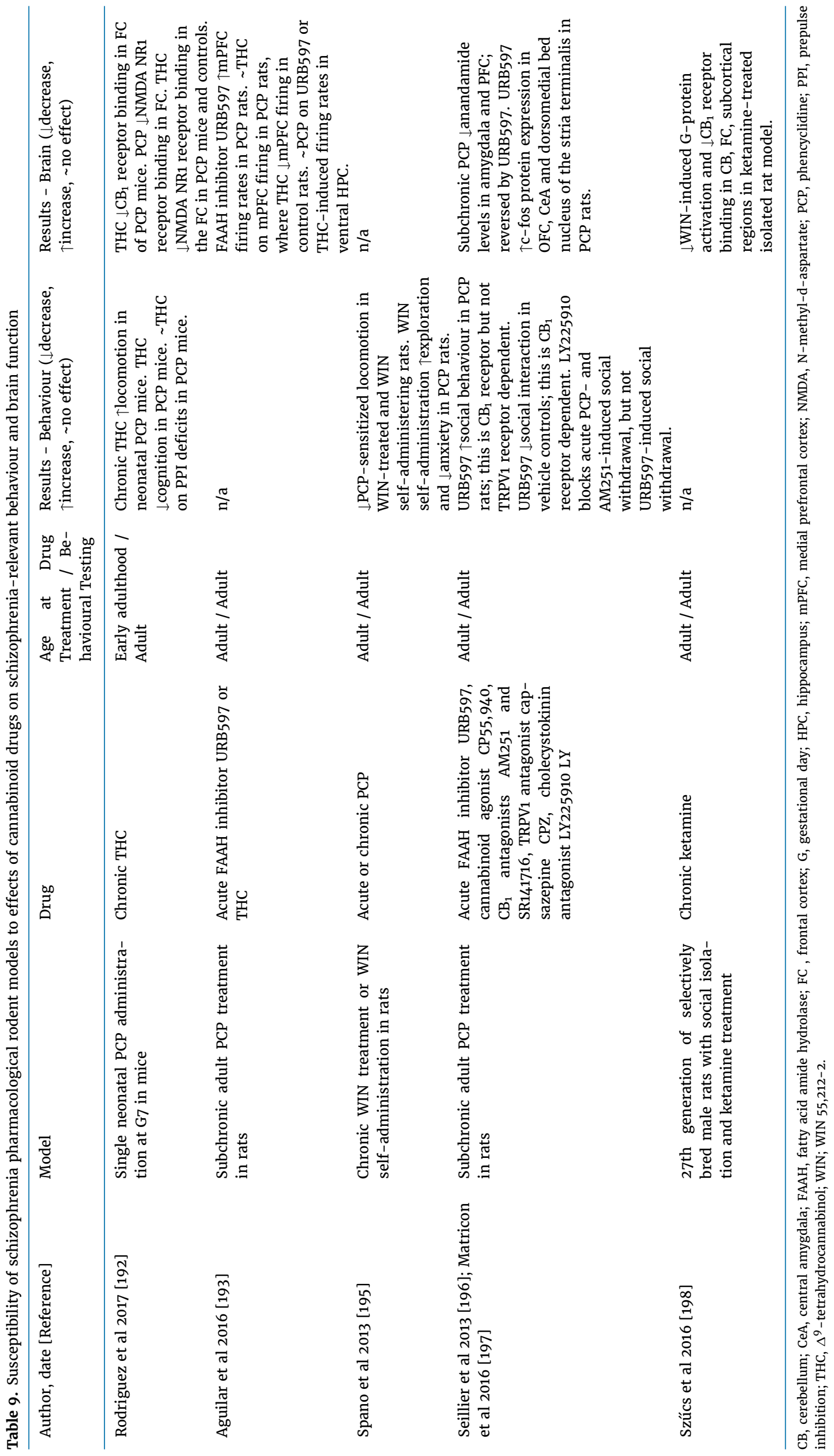


ated with drug susceptibility. The research reviewed above indicates that chronic nicotine has a range of effects on the brain in schizophrenia models, including reducing striatal $\mathrm{D}_{2}$ receptor mediated LTD in Snap-25 KO mice, increasing GAD67 and reelin mRNA in the cortex, hippocampus, striatum and cerebellum of reeler mice, and differential theta burst stimulated LTP in cortico-BLA synapses in Type III Nrg1 HET mice. Chronic THC alters $\mathrm{CB}_{1}$ receptor binding in the substantia nigra and $\mathrm{CB}_{1}$ protein levels in the hippocampus in genetic models (i.e. Nrg1 TM HET and DN-Disc1). Chronic THC also alters protein binding of NMDA and $5-\mathrm{HT}_{2 A}$ receptors in the cortex and hippocampus of Nrg1 TM HET mice, potentially reflecting genotype-specific effects of THC on locomotion and social behaviour. Endocannabinoid signalling (e.g. firing rates following FAAH inhibitor administration, WIN-induced g-protein activation or anandamide levels) are also altered in the PFC and amygdala and cerebellum in pharmacological (e.g. PCP) and two-hit models (e.g. ketamine and social isolation), suggesting changes to endocannabinoid function potentially reminiscent of endocannabinoid system changes in patients with schizophrenia [199-201]. The antipsychotic-like effects of CBD may be mediated by reversing changes to $\mathrm{PFC} \mathrm{CB}_{1}$ and NMDA receptor dysfunction and increasing GABA receptor binding in the hippocampus and PFC in schizophrenia models. Finally, while there has been limited examination of how psychostimulants affect neural function in schizophrenia models, elevated c-fos mRNA expression in the caudate-putamen following chronic haloperidol suggests sensitized dopaminergic function in reward regions and may also contribute to drug-seeking susceptibility.

\section{Conclusions}

There has been a vast addition to the preclinical literature investigating schizophrenia and drug abuse comorbidity since 2013, and it is becoming increasingly apparent that drug addiction behaviours and susceptibility to effects of abused drugs exist in many schizophrenia models. This is an exciting development, and suggests a burgeoning new field which could lead to breakthroughs in our understanding of comorbidity between schizophrenia and addiction. Importantly, in this review we have highlighted how often addiction-like behaviour is observed in different models of schizophrenia, particularly in genetic and neurodevelopmental models. We also found significant support for each hypothesis to explain drug susceptibility in schizophrenia: neurodevelopmental and some genetic models support the primary addiction hypothesis; genetic, neurodevelopmental and pharmacological models support the two-hit hypothesis, particularly for cannabinoids and nicotine, while genetic models often support the self-medication hypothesis for nicotine. Interestingly, this review found that the susceptibility of schizophrenia models to drug abuse appears to often implicate altered dopaminergic function (e.g. increased dopamine $\mathrm{D}_{2}$ receptor expression and dopamine metabolism), particularly in reward relevant regions such as the PFC and NAcc. This is relevant as changes in dopamine receptor expression are observed in drug abuse patients [5], and alterations to the dopaminergic system is consistent finding in schizophrenia, suggesting that schizophrenia susceptibility may alter drug reward pathways to elevate risk for drug abuse. It is interesting to note that cognitive impairment in some models (e.g. NVHL model) correlates with drug abuse susceptibility; investigating this in other models would be of considerable interest.

Furthermore, when examining susceptibility of schizophrenia models to abused drugs, there are effects on several neurotransmitter systems highly relevant to schizophrenia and addiction, primarily in mesocorticolimbic structures. Nicotine treatment has ameliorative effects on schizophrenia relevant behaviour in several models (e.g. genetic and pharmacological models, but not the NVHL model), and this may be dependent on actions at $\alpha 7$ nicotinergic receptors. Several models are more susceptible to the effects of cannabinoids such as THC and CBD on schizophrenia-relevant behaviours, and this is accompanied by complex changes in cannabinoid, glutamatergic, serotonergic and GABAergic receptor systems. Considering changes to these systems have all been reported in schizophrenia [208, 208-211], these findings not only validate the models used, but indicate how changes in these systems are relevant to both schizophrenia and drug susceptibility. Changes to specific receptor systems and subunits indicates which targets are specifically affected by drug exposure in schizophrenia, increasing our understanding of interactions between these disorders and potentially providing targets for future pharmacotherapies specifically designed to treat addiction in schizophrenia.

However, there are still several gaps in the literature which need to be addressed. To date, there has been very limited investigation into the molecular correlates of susceptibility to abused drugs. Also, most research has examined the response of schizophrenia models to effects of nicotine and cannabinoids on schizophrenia-like behaviours, yet behavioural and neural responses to other drugs of abuse (e.g. alcohol, psychostimulants, opioids), remains mostly unexplored. Other critical areas of future research include investigating addiction-like behaviour for non-psychostimulant drugs in genetic and pharmacological models of schizophrenia, as well as investigating potential sex-specific effects in terms of addiction-relevant behaviour. Poly-drug use has rarely been examined (but see a recent example: [75]), yet considering that poly-drug use is common in schizophrenia [212, 213], this is another research area with incredible potential. Addressing these gaps in the literature will thoroughly advance our understanding of the complex relationship between schizophrenia and drug abuse, and eventually help to better treat addiction in schizophrenia.

\section{Declarations}

\section{Author's Contributions}

RC conceptualised the review scope, VM and RC researched the topic and wrote the review, VM, JCO and RC edited the review, VM and RC approved the review prior to submission.

\section{Acknowledgements}

We would like to thank Dr Juan Olaya for his helpful comments on the manuscript.

\section{Funding}

RC is supported by the Molecular Medicine Research Group (Seed Funding 2017 and 2018, Western Sydney University) as well as the Ainsworth Medical Research Innovation Fund. In addition, RC is supported by the Rebecca Cooper Medical Research Foundation.

\section{Conflict of Interest Declaration}

This review was conducted in the absence of any commercial or financial relationships that could be construed as a potential conflict of interest. 


\section{Editorial Notes}

\section{History}

- Received: 2019-11-05

- Revised: 2019-12-22

- Accepted: 2020-01-08

- Published: 2020-01-16

\section{Editorial Checks}

- Plagiarism: Plagiarism detection software found no evidence of plagiarism.

- References: Zotero did not identify any references in the RetractionWatch database.

\section{Peer Review}

The review process for this paper was conducted double-blind because one of the authors is a member of the committee of management of the publisher, Episteme Health Inc. During review, neither the authors nor the reviewers were aware of each other's identities.

For the benefit of readers, reviewers are asked to write a public summary of their review to highlight the key strengths and weaknesses of the paper. Signing of reviews is optional.

\section{Reviewer 1 (Anonymous)}

This review aims to update the field on recent advances in our understanding of co-occurring schizophrenia and substance use disorders. The review focuses heavily on preclinical findings that have been published after 2013, and aims to address important questions related to how schizophrenia impacts vulnerability to substance use and how substance use alters the course of schizophrenia. The review is thorough (for the timepoints assessed), but sometimes the language is not specific.

\section{Reviewer 2 (Steven Simmons $\mathbb{D}$, Childrens Hospital of Philadelphia, United States.)}

This well-written and scholarly review discusses the complex interactions between substance use disorders (SUDs) and schizophrenia. It provides a major update to the field since a prior review published in 2013. Contained within are thorough descriptions of behavioral tests and measures used in animal studies that model both psychiatric conditions. The review frames studies through the lens of multiple theories attempting to account for the high comorbidity between SUDs and schiophrenia, including the "self-medication theory" (individuals with schizophrenia use drugs to manage symptoms of schizophrenia), the "primary addiction hypothesis" (predisposition to both psychiatric conditions are linked by common pathophysiology), and the "two-hit hypothesis" (genetic/environmental factors [first hit] initially predispose an individual to develop schizophrenia, and substance use [second hit] enables the manifestation of schizophrenia symptomatology). The review considers the underlying neurotransmitter systems and circuits that underlie behaviors associated with each disorder.

\section{Reviewer 3 (Anonymous)}

The authors of the review aim to summarise the literature surrounding the relationship between drugs of abuse and schizophrenia, in particular focusing on various rodent models, concentrating on studies published since 2013.

Drug addiction and abuse rates in the schizophrenia population is much higher than that of the general population, adding burden to an already highly burdensome disease. Given that both schizophrenia and drug addiction are complex disorders, many fundamental understanding is in flux. The review organises itself with two important and fundamental questions in mind - 1) whether schizophrenia primes individuals towards drug addiction and/or 2) whether drugs of abuse cause/exacerbate schizophrenia. The authors systematically review various types of rodent models and studies examining different drugs and molecular pathways, highlighting inconsistencies and areas that require further clarification.

The review is well constructed and laid out. It is a thorough summary and critique of the area of research. The review is well written and clear in its expression and offers a useful guide towards the future research in this field.

\section{References}

1. Perälä J, Suvisaari J, Saarni SI, Kuoppasalmi K, Isometsä E, Pirkola S, et al. Lifetime prevalence of psychotic and bipolar I disorders in a general population. Arch Gen Psychiatry. 2007;64(1):19-28. doi: 10.1001/archpsyc.64.1.19.

2. Andreasen NC. Symptoms, signs, and diagnosis of schizophrenia. Lancet. 1995;346(8973):477-81. doi: 10.1016/s0140-6736(95)91325-4.

3. Abel KM, Drake R, Goldstein JM. Sex differences in schizophrenia. Int Rev Psychiatry. 2010;22(5):417-28. doi: 10.3109/09540261.2010.515205.

4. Hunt GE, Large MM, Cleary M, Lai HMX, Saunders JB. Prevalence of comorbid substance use in schizophrenia spectrum disorders in community and clinical settings, 1990-2017: Systematic review and metaanalysis. Drug Alcohol Depend. 2018;191:234-258. doi: 10.1016/j.drugalcdep.2018.07.011.

5. Volkow ND. Substance use disorders in schizophreniaclinical implications of comorbidity. Schizophr Bull. 2009;35(3):469-72. doi: 10.1093/schbul/sbp016.

6. Kovasznay B, Fleischer J, Tanenberg-Karant M, Jandorf L, Miller AD, Bromet E. Substance use disorder and the early course of illness in schizophrenia and affective psychosis. Schizophr Bull. 1997;23(2):195-201. doi: 10.1093/schbul/23.2.195.

7. Addington J, Addington D. Substance abuse and cognitive functioning in schizophrenia. J Psychiatry Neurosci. 1997;22(2):99-104.

8. Hunt GE, Bergen J, Bashir M. Medication compliance and comorbid substance abuse in schizophrenia: impact on community survival 4 years after a relapse. Schizophr Res. 2002;54(3):253-64. doi: 10.1016/s0920-9964(01)002614.

9. Swartz MS, Wagner HR, Swanson JW, Stroup TS, McEvoy JP, Canive JM, et al. Substance use in persons with schizophrenia: baseline prevalence and correlates from the NIMH CATIE study. J Nerv Ment Dis. 2006;194(3):16472. doi: 10.1097/01.nmd.0000202575.79453.6e.

10. Schmidt LM, Hesse M, Lykke J. The impact of substance use disorders on the course of schizophreniaa 15-year follow-up study: dual diagnosis over 15 years. Schizophr Res. 2011;130(1-3):228-33. doi: 10.1016/j.schres.2011.04.011.

11. Janssen B, Gaebel W, Haerter M, Komaharadi F, Lindel B, Weinmann S. Evaluation of factors influencing medication compliance in inpatient treatment of psychotic disorders. Psychopharmacology (Berl). 2006;187(2):229-36. 
doi: 10.1007/s00213-006-0413-4.

12. Khokhar JY, Dwiel LL, Henricks AM, Doucette WT, Green AI. The link between schizophrenia and substance use disorder: A unifying hypothesis. Schizophr Res. 2018;194:78-85. doi: 10.1016/j.schres.2017.04.016.

13. Green AI, Drake RE, Brunette MF, Noordsy DL. Schizophrenia and co-occurring substance use disorder. Am J Psychiatry. 2007;164(3):402-8. doi: 10.1176/ajp.2007.164.3.402.

14. Khantzian EJ. The self-medication hypothesis of substance use disorders: a reconsideration and recent applications. Harv Rev Psychiatry. 1997;4(5):231-44. doi: 10.3109/10673229709030550.

15. Boggs DL, Surti TS, Esterlis I, Pittman B, Cosgrove $\mathrm{K}$, Sewell RA, et al. Minimal effects of prolonged smoking abstinence or resumption on cognitive performance challenge the "self-medication" hypothesis in schizophrenia. Schizophr Res. 2018;194:62-69. doi: 10.1016/j.schres.2017.03.047.

16. Rabin RA, Kozak K, Zakzanis KK, Remington G, George TP. Effects of extended cannabis abstinence on clinical symptoms in cannabis dependent schizophrenia patients versus non-psychiatric controls. Schizophr Res. 2018;194:55-61. doi: 10.1016/j.schres.2017.03.010.

17. Chambers RA, Krystal JH, Self DW. A neurobiological basis for substance abuse comorbidity in schizophrenia. Biol Psychiatry. 2001;50(2):71-83. doi: 10.1016/s00063223(01)01134-9.

18. Bayer TA, Falkai P, Maier W. Genetic and non-genetic vulnerability factors in schizophrenia: the basis of the "two hit hypothesis". J Psychiatr Res. 1999;33(6):543-8. doi: 10.1016/s0022-3956(99)00039-4.

19. Mueser KT, Yarnold PR, Levinson DF, Singh H, Bellack AS, Kee K, et al. Prevalence of substance abuse in schizophrenia: demographic and clinical correlates. Schizophr Bull. 1990;16(1):31-56. doi: 10.1093/schbul/16.1.31.

20. Jones CA, Watson DJ, Fone KC. Animal models of schizophrenia. Br J Pharmacol. 2011;164(4):1162-94. doi: 10.1111/j.1476-5381.2011.01386.x.

21. Lewis DA, Levitt P. Schizophrenia as a disorder of neurodevelopment. Annu Rev Neurosci. 2002;25:409-32. doi: 10.1146/annurev.neuro.25.112701.142754.

22. Pearlson GD. Neurobiology of schizophrenia. Ann Neurol. 2000;48(4):556-66. doi: 10.1002/15318249(200010)48:4<556::AID-ANA2>3.0.CO;2-2.

23. Foussias G, Siddiqui I, Fervaha G, Agid O, Remington G. Dissecting negative symptoms in schizophrenia: opportunities for translation into new treatments. J Psychopharmacol. 2015;29(2):116-26. doi: 10.1177/0269881114562092.

24. Pratt J, Winchester C, Dawson N, Morris B. Advancing schizophrenia drug discovery: optimizing rodent models to bridge the translational gap. Nat Rev Drug Discov. 2012;11(7):560-79. doi: 10.1038/nrd3649.

25. Javitt DC. Glutamate and schizophrenia: phencyclidine, N-methyl-D-aspartate receptors, and dopamineglutamate interactions. Int Rev Neurobiol. 2007;78:69108. doi: 10.1016/S0074-7742(06)78003-5.

26. Bussey TJ, Holmes A, Lyon L, Mar AC, McAllister KA, Nithianantharajah $\mathrm{J}$, et al. New translational assays for preclinical modelling of cognition in schizophrenia: the touchscreen testing method for mice and rats. Neuropharmacology. 2012;62(3):1191-203. doi: 10.1016/j.neuropharm.2011.04.011.

27. Kim $\mathrm{CH}$, Hvoslef-Eide M, Nilsson SR, Johnson MR, Herbert BR, Robbins TW, et al. The continuous performance test (rCPT) for mice: a novel operant touchscreen test of attentional function. Psychopharmacology
(Berl). 2015;232(21-22):3947-66. doi: 10.1007/s00213015-4081-0.

28. Bardo MT, Bevins RA. Conditioned place preference: what does it add to our preclinical understanding of drug reward? Psychopharmacology (Berl). 2000;153(1):31-43. doi: 10.1007/s002130000569.

29. Huston JP, Silva MA, Topic B, Müller CP. What's conditioned in conditioned place preference? Trends Pharmacol Sci. 2013;34(3):162-6. doi: 10.1016/j.tips.2013.01.004.

30. Tzschentke TM. Measuring reward with the conditioned place preference paradigm: a comprehensive review of drug effects, recent progress and new issues. Prog Neurobiol. 1998;56(6):613-72. doi: 10.1016/s03010082(98)00060-4.

31. Tzschentke TM. Measuring reward with the conditioned place preference (CPP) paradigm: update of the last decade. Addict Biol. 2007;12(3-4):227-462. doi: 10.1111/j.1369-1600.2007.00070.x.

32. Robinson TE, Berridge KC. The psychology and neurobiology of addiction: an incentive-sensitization view. Addiction. 2000;95 Suppl 2:S91-117. doi: $10.1080 / 09652140050111681$.

33. Vezina P, Leyton M. Conditioned cues and the expression of stimulant sensitization in animals and humans. Neuropharmacology. 2009;56 Suppl 1:160-8. doi: 10.1016/j.neuropharm.2008.06.070.

34. Steketee JD, Kalivas PW. Drug wanting: behavioral sensitization and relapse to drug-seeking behavior. Pharmacol Rev. 2011;63(2):348-65. doi: 10.1124/pr.109.001933.

35. Thomsen $M$, Caine $S B$. Intravenous drug selfadministration in mice: practical considerations. Behav Genet. 2007;37(1):101-18. doi: 10.1007/s10519-0069097-0.

36. Farrell MR, Schoch H, Mahler SV. Modeling cocaine relapse in rodents: Behavioral considerations and circuit mechanisms. Prog Neuropsychopharmacol Biol Psychiatry. 2018;87(Pt A):33-47. doi: 10.1016/j.pnpbp.2018.01.002.

37. Negus SS, Miller LL. Intracranial self-stimulation to evaluate abuse potential of drugs. Pharmacol Rev. 2014;66(3):869-917. doi: 10.1124/pr.112.007419.

38. Carlezon J W A, Chartoff EH. Intracranial selfstimulation (ICSS) in rodents to study the neurobiology of motivation. Nat Protoc. 2007;2(11):2987-95. doi: 10.1038/nprot.2007.441.

39. Ng E, McGirr A, Wong AH, Roder JC. Using rodents to model schizophrenia and substance use comorbidity. Neurosci Biobehav Rev. 2013;37(5):896-910. doi: 10.1016/j.neubiorev.2013.03.025.

40. Schneider M. Adolescence as a vulnerable period to alter rodent behavior. Cell Tissue Res. 2013;354(1):99-106. doi: 10.1007/s00441-013-1581-2.

41. Nestler EJ, Hyman SE. Animal models of neuropsychiatric disorders. Nat Neurosci. 2010;13(10):1161-9. doi: $10.1038 / \mathrm{nn} .2647$.

42. Hoffman KL. Role of murine models in psychiatric illness drug discovery: a dimensional view. Expert Opin Drug Discov. 2013;8(7):865-77. doi: 10.1517/17460441.2013.797959.

43. Keller J R W, Maisonneuve IM, Carlson JN, Glick SD. Within-subject sensitization of striatal dopamine release after a single injection of cocaine: an in vivo microdialysis study. Synapse. 1992;11(1):28-34. doi: 10.1002/syn.890110105.

44. Kashihara K, Hamamura T, Okumura K, Otsuki S. Methamphetamine-induced dopamine release in the medial frontal cortex of freely moving rats. Jpn J Psychiatry Neurol. 1991;45(3):677-80. doi: 10.1111/j.1440- 
1819.1991.tbo1190.x.

45. Remington G, Agid O, Foussias G. Schizophrenia as a disorder of too little dopamine: implications for symptoms and treatment. Expert Rev Neurother. 2011;11(4):589-607. doi: 10.1586/ern.10.191.

46. Brunelin J, Fecteau S, Suaud-Chagny MF. Abnormal striatal dopamine transmission in schizophrenia. Curr Med Chem. 2013;20(3):397-404. doi: 10.2174/0929867311320030011.

47. Seeman P. Schizophrenia thalamus imaging: low benzamide binding to dopamine D2 receptors suggests fewer D2Short receptors and fewer presynaptic terminals. Psychiatry Res. 2013;214(3):175-80. doi: 10.1016/j.pscychresns.2013.09.013.

48. Clark AM, Leroy F, Martyniuk KM, Feng W, McManus E, Bailey MR, et al. Dopamine D2 Receptors in the Paraventricular Thalamus Attenuate Cocaine Locomotor Sensitization. eNeuro. 2017;4(5). doi: 10.1523/ENEURO.022717.2017.

49. Dahoun T, Trossbach SV, Brandon NJ, Korth C, Howes OD. The impact of Disrupted-in-Schizophrenia 1 (DISC1) on the dopaminergic system: a systematic review. Transl Psychiatry. 2017;7(1):e1015. doi: 10.1038/tp.2016.282.

50. Brandon NJ, Sawa A. Linking neurodevelopmental and synaptic theories of mental illness through DISC1. Nat Rev Neurosci. 2011;12(12):707-22. doi: 10.1038/nrn3120.

51. Wong AH, Josselyn SA. Caution When Diagnosing Your Mouse With Schizophrenia: The Use and Misuse of Model Animals for Understanding Psychiatric Disorders. Biol Psychiatry. 2016;79(1):32-8. doi: 10.1016/j.biopsych.2015.04.023.

52. Gancarz A, Jouroukhin Y, Saito A, Shevelkin A, Mueller LE, Kamiya A, et al. DISC1 signaling in cocaine addiction: Towards molecular mechanisms of co-morbidity. Neurosci Res. 2016;105:70-4. doi: 10.1016/j.neures.2015.09.001.

53. Lee KY, Ahn YM, Joo EJ, Joo YH, Chang JS, Yoo HY, et al. Partial evidence of an association between epidermal growth factor $\mathrm{A} 61 \mathrm{G}$ polymorphism and age at onset in male schizophrenia. Neurosci Res. 2006;56(4):356-62. doi: 10.1016/j.neures.2006.08.004.

54. Hanninen K, Katila H, Anttila S, Rontu R, Maaskola J, Hurme $M$, et al. Epidermal growth factor a61g polymorphism is associated with the age of onset of schizophrenia in male patients. J Psychiatr Res. 2007;41(1-2):8-14. doi: 10.1016/j.jpsychires.2005.07.001.

55. Eda T, Mizuno M, Araki K, Iwakura Y, Namba H, Sotoyama $\mathrm{H}$, et al. Neurobehavioral deficits of epidermal growth factor-overexpressing transgenic mice: impact on dopamine metabolism. Neurosci Lett. 2013;547:21-5. doi: 10.1016/j.neulet.2013.04.055.

56. Balu DT. The NMDA Receptor and Schizophrenia: From Pathophysiology to Treatment. In: Schwarcz R, Coyle JT, editors. Neuropharmacology: a tribute to Joseph T. Coyle. vol. 76 of Advances in Pharmacology. Amsterdam: Academic Press; 2016. p. 351-82. doi: 10.1016/bs.apha.2016.01.006.

57. Puhl MD, Berg AR, Bechtholt AJ, Coyle JT. Availability of N-Methyl-d-Aspartate Receptor Coagonists Affects Cocaine-Induced Conditioned Place Preference and Locomotor Sensitization: Implications for Comorbid Schizophrenia and Substance Abuse. J Pharmacol Exp Ther. 2015;353(3):465-70. doi: 10.1124/jpet.115.223099.

58. Singer $\mathrm{P}$, Yee BK, Feldon J, Iwasato $\mathrm{T}$, Itohara $\mathrm{S}$, Grampp $\mathrm{T}$, et al. Altered mnemonic functions and resistance to N-METHYL-d-Aspartate receptor antagonism by forebrain conditional knockout of glycine transporter 1. Neuroscience. 2009;161(2):635-54. doi: 10.1016/j.neuroscience.2009.03.056.
59. Yee BK, Balic E, Singer P, Schwerdel C, Grampp T, Gabernet $\mathrm{L}$, et al. Disruption of glycine transporter 1 restricted to forebrain neurons is associated with a procognitive and antipsychotic phenotypic profile. J Neurosci. 2006;26(12):3169-81. doi: 10.1523/JNEUROSCI.512005.2006.

60. Puhl MD, Mintzopoulos D, Jensen JE, Gillis TE, Konopaske GT, Kaufman MJ, et al. In vivo magnetic resonance studies reveal neuroanatomical and neurochemical abnormalities in the serine racemase knockout mouse model of schizophrenia. Neurobiol Dis. 2015;73:269-74. doi: 10.1016/j.nbd.2014.10.009.

61. Matveeva TM, Pisansky MT, Young A, Miller RF, Gewirtz JC. Sociality deficits in serine racemase knockout mice. Brain Behav. 2019;9(10):e01383. doi: 10.1002/brb3.1383.

62. Basu AC, Tsai GE, Ma CL, Ehmsen JT, Mustafa AK, Han $\mathrm{L}$, et al. Targeted disruption of serine racemase affects glutamatergic neurotransmission and behavior. Mol Psychiatry. 2009;14(7):719-27. doi: 10.1038/mp.2008.130.

63. Puhl MD, Desai RI, Takagi S, Presti KT, Doyle MR, Donahue RJ, et al. N-Methyl-d-aspartate receptor coagonist availability affects behavioral and neurochemical responses to cocaine: insights into comorbid schizophrenia and substance abuse. Addict Biol. 2019;24(1):40-50. doi: 10.1111/adb.12577.

64. Benneyworth MA, Coyle JT. Altered acquisition and extinction of amphetamine-paired context conditioning in genetic mouse models of altered NMDA receptor function. Neuropsychopharmacology. 2012;37(11):2496-504. doi: 10.1038/npp.2012.108.

65. Brady AM. The Neonatal Ventral Hippocampal Lesion (NVHL) Rodent Model of Schizophrenia. Curr Protoc Neurosci. 2016;77:9.55.1-9.55.17. doi: 10.1002/cpns.15.

66. Tseng KY, Chambers RA, Lipska BK. The neonatal ventral hippocampal lesion as a heuristic neurodevelopmental model of schizophrenia. Behav Brain Res. 2009;204(2):295-305. doi: 10.1016/j.bbr.2008.11.039.

67. Lipska BK, Weinberger DR. To model a psychiatric disorder in animals: schizophrenia as a reality test. Neuropsychopharmacology. 2000;23(3):223-39. doi: 10.1016/S0893-133X(00)00137-8.

68. Lipska BK, Weinberger DR. A neurodevelopmental model of schizophrenia: neonatal disconnection of the hippocampus. Neurotox Res. 2002;4(5-6):469-475. doi: 10.1080/1029842021000022089.

69. Gallo A, Bouchard C, Fortier E, Ducrot C, Rompré PP. Cannabinoids reward sensitivity in a neurodevelopmental animal model of schizophrenia: a brain stimulation reward study. Eur Neuropsychopharmacol. 2014;24(9):1534-45. doi: 10.1016/j.euroneuro.2014.07.003.

70. Brady AM, McCallum SE, Glick SD, O'Donnell P. Enhanced methamphetamine self-administration in a neurodevelopmental rat model of schizophrenia. Psychopharmacology (Berl). 2008;200(2):205-15. doi: 10.1007/s00213008-1195-7.

71. Chambers RA, McClintick JN, Sentir AM, Berg SA, Runyan $\mathrm{M}$, Choi $\mathrm{KH}$, et al. Cortical-striatal gene expression in neonatal hippocampal lesion (NVHL)-amplified cocaine sensitization. Genes Brain Behav. 2013;12(5):564-75. doi: 10.1111/gbb.12051.

72. Rao KN, Sentir AM, Engleman EA, Bell RL, Hulvershorn LA, Breier A, et al. Toward early estimation and treatment of addiction vulnerability: radial arm maze and $\mathrm{N}$-acetyl cysteine before cocaine sensitization or nicotine self-administration in neonatal ventral hippocampal lesion rats. Psychopharmacology (Berl). 2016;233(2324):3933-3945. doi: 10.1007/s00213-016-4421-8. 
73. Karlsson RM, Kircher DM, Shaham Y, O'Donnell P. Exaggerated cue-induced reinstatement of cocaine seeking but not incubation of cocaine craving in a developmental rat model of schizophrenia. Psychopharmacology (Berl). 2013;226(1):45-51. doi: 10.1007/s00213-012-2882-y.

74. Berg SA, Sentir AM, Cooley BS, Engleman EA, Chambers RA. Nicotine is more addictive, not more cognitively therapeutic in a neurodevelopmental model of schizophrenia produced by neonatal ventral hippocampal lesions. Addict Biol. 2014;19(6):1020-31. doi: 10.1111/adb.12082.

75. Sentir AM, Bell RL, Engleman EA, Chambers RA. Polysubstance addiction vulnerability in mental illness: Concurrent alcohol and nicotine self-administration in the neurodevelopmental hippocampal lesion rat model of schizophrenia. Addict Biol. 2018;doi: 10.1111/adb.12704.

76. Duncan SC, Alpert A, Duncan TE, Hops H. Adolescent alcohol use development and young adult outcomes. Drug Alcohol Depend. 1997;49(1):39-48. doi: 10.1016/s03768716(97)00137-3.

77. Jeanblanc J, Balguerie K, Coune F, Legastelois R, Jeanblanc V, Naassila M. Light alcohol intake during adolescence induces alcohol addiction in a neurodevelopmental model of schizophrenia. Addict Biol. 2015;20(3):490-9. doi: 10.1111/adb.12146.

78. Khokhar JY, Todd TP. Behavioral predictors of alcohol drinking in a neurodevelopmental rat model of schizophrenia and co-occurring alcohol use disorder. Schizophr Res. 2018;194:91-97. doi: 10.1016/j.schres.2017.02.029.

79. Spiller KJ, Bi GH, He Y, Galaj E, Gardner EL, Xi ZX. Cannabinoid $\mathrm{CB} 1$ and $\mathrm{CB} 2$ receptor mechanisms underlie cannabis reward and aversion in rats. Br J Pharmacol. 2019;176(9):1268-1281. doi: 10.1111/bph.14625.

80. Ksir C, Hart CL. Cannabis and Psychosis: a Critical Overview of the Relationship. Curr Psychiatry Rep. 2016;18(2):12. doi: 10.1007/s11920-015-0657-y.

81. Hamilton I. Cannabis, psychosis and schizophrenia: unravelling a complex interaction. Addiction. 2017;112(9):1653-1657. doi: 10.1111/add.13826.

82. Valjent E, Maldonado R. A behavioural model to reveal place preference to delta 9-tetrahydrocannabinol in mice. Psychopharmacology (Berl). 2000;147(4):436-8. doi: 10.1007/s002130050013.

83. Vlachou S, Nomikos GG, Stephens DN, Panagis G. Lack of evidence for appetitive effects of Delta 9tetrahydrocannabinol in the intracranial self-stimulation and conditioned place preference procedures in rodents. Behav Pharmacol. 2007;18(4):311-9. doi: 10.1097/FBP.ob013e3282186cf2.

84. Hempel BJ, Wakeford AG, Clasen MM, Friar MA, Riley AL. Delta-9-tetrahydrocannabinol (THC) history fails to affect THC's ability to induce place preferences in rats. Pharmacol Biochem Behav. 2016;144:1-6. doi: 10.1016/j.pbb.2016.02.007.

85. Gallo A, Bouchard C, Rompré PP. Animals with a schizophrenia-like phenotype are differentially sensitive to the motivational effects of cannabinoid agonists in conditioned place preference. Behav Brain Res. 2014;268:202-12. doi: 10.1016/j.bbr.2014.04.020.

86. Govaerts SJ, Hermans E, Lambert DM. Comparison of cannabinoid ligands affinities and efficacies in murine tissues and in transfected cells expressing human recombinant cannabinoid receptors. Eur J Pharm Sci. 2004;23(3):233-43. doi: 10.1016/j.ejps.2004.07.013.

87. Meyer U. Prenatal poly(i:C) exposure and other developmental immune activation models in rodent systems. Biol Psychiatry. 2014;75(4):307-15. doi: 10.1016/j.biopsych.2013.07.011.
88. Meyer U, Yee BK, Feldon J. The neurodevelopmental impact of prenatal infections at different times of pregnancy: the earlier the worse? Neuroscientist. 2007;13(3):241-56. doi: 10.1177/1073858406296401.

89. Borcoi AR, Patti CL, Zanin KA, Hollais AW, SantosBaldaia R, Ceccon LM, et al. Effects of prenatal immune activation on amphetamine-induced addictive behaviors: Contributions from animal models. Prog Neuropsychopharmacol Biol Psychiatry. 2015;63:63-9. doi: 10.1016/j.pnpbp.2015.05.015.

90. Chen L, Perez SM, Lodge DJ. An augmented dopamine system function is present prior to puberty in the methylazoxymethanol acetate rodent model of schizophrenia. Dev Neurobiol. 2014;74(9):907-17. doi: 10.1002/dneu.22172.

91. Labouesse MA, Langhans W, Meyer U. Abnormal contextreward associations in an immune-mediated neurodevelopmental mouse model with relevance to schizophrenia. Transl Psychiatry. 2015;5:e637. doi: 10.1038/tp.2015.129.

92. Carelli RM, Wondolowski J. Anatomic distribution of reinforcer selective cell firing in the core and shell of the nucleus accumbens. Synapse. 2006;59(2):69-73. doi: $10.1002 /$ syn.20217.

93. Bolton JL, Ruiz CM, Rismanchi N, Sanchez GA, Castillo E, Huang J, et al. Early-life adversity facilitates acquisition of cocaine self-administration and induces persistent anhedonia. Neurobiol Stress. 2018;8:57-67. doi: 10.1016/j.ynstr.2018.01.002.

94. Featherstone RE, Burton CL, Coppa-Hopman R, Rizos Z, Sinyard J, Kapur S, et al. Gestational treatment with methylazoxymethanol (MAM) that disrupts hippocampaldependent memory does not alter behavioural response to cocaine. Pharmacol Biochem Behav. 2009;93(4):382-90. doi: 10.1016/j.pbb.2009.05.010.

95. Santos-Toscano R, Borcel E, Ucha M, Orihuel J, Capellan $\mathrm{R}$, Roura-Martinez D, et al. Unaltered cocaine self-administration in the prenatal LPS rat model of schizophrenia. Prog Neuropsychopharmacol Biol Psychiatry. 2016;69:38-48. doi: 10.1016/j.pnpbp.2016.04.008.

96. Ruda-Kucerova J, Babinska Z, Amchova P, Stark T, Drago F, Sulcova A, et al. Reactivity to addictive drugs in the methylazoxymethanol (MAM) model of schizophrenia in male and female rats. World J Biol Psychiatry. 2017;18(2):129-142. doi: 10.1080/15622975.2016.1190032.

97. Ruda-Kucerova J, Babinska Z, Stark T, Micale V. Suppression of Methamphetamine Self-Administration by Ketamine Pre-treatment Is Absent in the Methylazoxymethanol (MAM) Rat Model of Schizophrenia. Neurotox Res. 2017;32(1):121-133. doi: 10.1007/s12640-0179718-9.

98. Said N, Lakehayli S, El Khachibi M, El Ouahli M, Nadifi S, Hakkou F, et al. Prenatal stress induces vulnerability to nicotine addiction and alters D2 receptors' expression in the nucleus accumbens in adult rats. Neuroscience. 2015;304:279-85. doi: 10.1016/j.neuroscience.2015.07.029.

99. Brown RW, Schlitt MA, Owens AS, DePreter CC, Cummins ED, Kirby SL, et al. Effects of Environmental Enrichment on Nicotine Sensitization in Rats Neonatally Treated with Quinpirole: Analyses of Glial Cell Line-Derived Neurotrophic Factor and Implications towards Schizophrenia. Dev Neurosci. 2018;40(1):64-72. doi: 10.1159/000486391.

100. Waterhouse U, Brennan KA, Ellenbroek BA. Nicotine selfadministration reverses cognitive deficits in a rat model for schizophrenia. Addict Biol. 2018;23(2):620-630. doi: 10.1111/adb.12517.

101. Weeks JJ, Rupprecht LE, Grace AA, Donny EC, Sved AF. Nicotine self-administration is not increased in the MAM rodent model of schizophrenia. Nicotine Tob Res. 
2019;doi: 10.1093/ntr/ntz048.

102. Wang J, Carnicella S, Ahmadiantehrani S, He DY, Barak $\mathrm{S}$, Kharazia V, et al. Nucleus accumbens-derived glial cell line-derived neurotrophic factor is a retrograde enhancer of dopaminergic tone in the mesocorticolimbic system. J Neurosci. 2010;30(43):14502-12. doi: 10.1523/JNEUROSCI.3909-10.2010.

103. Blednov YA, Benavidez JM, Geil C, Perra S, Morikawa $\mathrm{H}$, Harris RA. Activation of inflammatory signaling by lipopolysaccharide produces a prolonged increase of voluntary alcohol intake in mice. Brain Behav Immun. 2011;25 Suppl 1:S92-S105. doi: 10.1016/j.bbi.2011.01.008.

104. Chappell AM, Carter E, McCool BA, Weiner JL. Adolescent rearing conditions influence the relationship between initial anxiety-like behavior and ethanol drinking in male Long Evans rats. Alcohol Clin Exp Res. 2013;37 Suppl 1:E394-403. doi: 10.1111/j.1530-0277.2012.01926.x.

105. Skelly MJ, Chappell AE, Carter E, Weiner JL. Adolescent social isolation increases anxiety-like behavior and ethanol intake and impairs fear extinction in adulthood: Possible role of disrupted noradrenergic signaling. Neuropharmacology. 2015;97:149-59. doi: 10.1016/j.neuropharm.2015.05.025.

106. Lopez MF, Doremus-Fitzwater TL, Becker HC. Chronic social isolation and chronic variable stress during early development induce later elevated ethanol intake in adult C57BL/6J mice. Alcohol. 2011;45(4):355-64. doi: 10.1016/j.alcohol.2010.08.017.

107. Holgate JY, Garcia H, Chatterjee S, Bartlett SE. Social and environmental enrichment has different effects on ethanol and sucrose consumption in mice. Brain Behav. 2017;7(8):e00767. doi: 10.1002/brb3.767.

108. Lee RS, Oswald LM, Wand GS. Early Life Stress as a Predictor of Co-Occurring Alcohol Use Disorder and PostTraumatic Stress Disorder. Alcohol Res. 2018;39(2):147159.

109. Enoch MA. The role of early life stress as a predictor for alcohol and drug dependence. Psychopharmacology (Berl). 2011;214(1):17-31. doi: 10.1007/s00213-010-1916-6.

110. Fletcher PJ, Li Z, Coen KM, Lê AD. Acquisition of nicotine self-administration in amphetamine and phencyclidine models of schizophrenia: A role for stress? Schizophr Res. 2018;194:98-106. doi: 10.1016/j.schres.2017.02.028.

111. Baird JP, Turgeon S, Wallman A, Hulick V. Behavioral processes mediating phencyclidine-induced decreases in voluntary sucrose consumption. Pharmacol Biochem Behav. 2008;88(3):272-9. doi: 10.1016/j.pbb.2007.08.011.

112. Spielewoy C, Markou A. Withdrawal from chronic phencyclidine treatment induces long-lasting depression in brain reward function. Neuropsychopharmacology. 2003;28(6):1106-16. doi: 10.1038/sj.npp.1300124.

113. Chiappelli J, Chen S, Hackman A, Elliot Hong L. Evidence for differential opioid use disorder in schizophrenia in an addiction treatment population. Schizophr Res. 2018;194:26-31. doi: 10.1016/j.schres.2017.05.004.

114. Leal G, Bramham CR, Duarte CB. BDNF and Hippocampal Synaptic Plasticity. In: Litwack G, editor. Neurotrophins. vol. 104 of Vitamins and Hormones. Amsterdam: Academic Press; 2017. p. 153-195. doi: 10.1016/bs.vh.2016.10.004.

115. Bekinschtein P, Cammarota M, Medina JH. BDNF and memory processing. Neuropharmacology. 2014;76 Pt C:677-83. doi: 10.1016/j.neuropharm.2013.04.024.

116. Chen DC, Wang J, Wang B, Yang SC, Zhang CX, Zheng YL, et al. Decreased levels of serum brain-derived neurotrophic factor in drug-naive first-episode schizophrenia: relationship to clinical phenotypes. Psychopharmacology (Berl). 2009;207(3):375-80. doi: 10.1007/s00213-
009-1665-6.

117. Man L, Lv X, Du XD, Yin G, Zhu X, Zhang Y, et al. Cognitive impairments and low BDNF serum levels in first-episode drug-naive patients with schizophrenia. Psychiatry Res. 2018;263:1-6. doi: 10.1016/j.psychres.2018.02.034.

118. Jena M, Ranjan R, Mishra BR, Mishra A, Nath S, Sahu P, et al. Effect of lurasidone vs olanzapine on neurotrophic biomarkers in unmedicated schizophrenia: A randomized controlled trial. J Psychiatr Res. 2019;112:1-6. doi: 10.1016/j.jpsychires.2019.02.007.

119. Hashimoto T, Bergen SE, Nguyen QL, Xu B, Monteggia LM, Pierri JN, et al. Relationship of brain-derived neurotrophic factor and its receptor TrkB to altered inhibitory prefrontal circuitry in schizophrenia. J Neurosci. 2005;25(2):372-83. doi: 10.1523/JNEUROSCI.403504.2005.

120. Saylor AJ, McGinty JF. Amphetamine-induced locomotion and gene expression are altered in BDNF heterozygous mice. Genes Brain Behav. 2008;7(8):906-14. doi: 10.1111/j.1601-183X.2008.00430.x.

121. Manning EE, van den Buuse M. BDNF deficiency and young-adult methamphetamine induce sex-specific effects on prepulse inhibition regulation. Front Cell Neurosci. 2013;7:92. doi: 10.3389/fncel.2013.00092.

122. Braff DL, Geyer MA, Swerdlow NR. Human studies of prepulse inhibition of startle: normal subjects, patient groups, and pharmacological studies. Psychopharmacology (Berl). 2001;156(2-3):234-58. doi: 10.1007/s002130100810.

123. Manning EE, Halberstadt AL, van den Buuse M. BDNFDeficient Mice Show Reduced Psychosis-Related Behaviors Following Chronic Methamphetamine. Int J Neuropsychopharmacol. 2016;19(4). doi: 10.1093/ijnp/pyv116.

124. Manning EE, van den Buuse M. Altered social cognition in male BDNF heterozygous mice and following chronic methamphetamine exposure. Behav Brain Res. 2016;305:181-5. doi: 10.1016/j.bbr.2016.03.014.

125. Arime Y, Fukumura R, Miura I, Mekada K, Yoshiki A, Wakana S, et al. Effects of background mutations and single nucleotide polymorphisms (SNPs) on the Disc1 L10oP behavioral phenotype associated with schizophrenia in mice. Behav Brain Funct. 2014;10:45. doi: 10.1186/17449081-10-45.

126. Baca M, Allan AM, Partridge LD, Wilson MC. Geneenvironment interactions affect long-term depression (LTD) through changes in dopamine receptor affinity in Snap25 deficient mice. Brain Res. 2013;1532:85-98. doi: 10.1016/j.brainres.2013.08.012.

127. Tobacco and Genetics Consortium. Genome-wide metaanalyses identify multiple loci associated with smoking behavior. Nat Genet. 2010;42(5):441-7. doi: $10.1038 / \mathrm{ng} .571$.

128. Koukouli F, Rooy M, Tziotis D, Sailor KA, O'Neill HC, Levenga $\mathrm{J}$, et al. Nicotine reverses hypofrontality in animal models of addiction and schizophrenia. Nat Med. 2017;23(3):347-354. doi: 10.1038/nm.4274.

129. Korostishevsky M, Kaganovich M, Cholostoy A, Ashkenazi $M$, Ratner $Y$, Dahary $D$, et al. Is the G72/G30 locus associated with schizophrenia? single nucleotide polymorphisms, haplotypes, and gene expression analysis. Biol Psychiatry. 2004;56(3):169-76. doi: 10.1016/j.biopsych.2004.04.006.

130. Hambsch B, Keyworth H, Lind J, Otte DM, Racz I, Kitchen I, et al. Chronic nicotine improves short-term memory selectively in a G72 mouse model of schizophrenia. Br J Pharmacol. 2014;171(7):1758-71. doi: 10.1111/bph.12578.

131. Zanos P, Keyworth H, Georgiou P, Hambsch B, Otte DM, 
Kitchen I, et al. Chronic nicotine administration restores brain region specific upregulation of oxytocin receptor binding levels in a G72 mouse model of schizophrenia. Eur J Neurosci. 2018;doi: 10.1111/ejn.14155.

132. Grayson DR, Jia X, Chen Y, Sharma RP, Mitchell CP, Guidotti A, et al. Reelin promoter hypermethylation in schizophrenia. Proc Natl Acad Sci U S A. 2005;102(26):9341-6. doi: 10.1073/pnas.0503736102.

133. Tueting $P$, Costa E, Dwivedi $Y$, Guidotti A, Impagnatiello F, Manev R, et al. The phenotypic characteristics of heterozygous reeler mouse. Neuroreport. 1999;10(6):132934. doi: 10.1097/00001756-199904260-00032.

134. Qiu S, Korwek KM, Pratt-Davis AR, Peters M, Bergman MY, Weeber EJ. Cognitive disruption and altered hippocampus synaptic function in Reelin haploinsufficient mice. Neurobiol Learn Mem. 2006;85(3):228-42. doi: 10.1016/j.nlm.2005.11.001.

135. Macrì S, Biamonte F, Romano E, Marino R, Keller F, Laviola G. Perseverative responding and neuroanatomical alterations in adult heterozygous reeler mice are mitigated by neonatal estrogen administration. Psychoneuroendocrinology. 2010;35(9):1374-87. doi: 10.1016/j.psyneuen.2010.03.012.

136. Maloku E, Covelo IR, Hanbauer I, Guidotti A, Kadriu B, $\mathrm{Hu} \mathrm{Q}$, et al. Lower number of cerebellar Purkinje neurons in psychosis is associated with reduced reelin expression. Proc Natl Acad Sci U S A. 2010;107(9):4407-11. doi: 10.1073/pnas.0914483107.

137. Biamonte F, Assenza G, Marino R, D'Amelio M, Panteri $\mathrm{R}$, Caruso $\mathrm{D}$, et al. Interactions between neuroactive steroids and reelin haploinsufficiency in Purkinje cell survival. Neurobiol Dis. 2009;36(1):103-15. doi: 10.1016/j.nbd.2009.07.001.

138. Romano E, Fuso A, Laviola G. Nicotine restores Wt-like levels of reelin and GAD67 gene expression in brain of heterozygous reeler mice. Neurotox Res. 2013;24(2):20515. doi: $10.1007 / \mathrm{s} 12640-013-9378-3$.

139. Romano E, De Angelis F, Ulbrich L, De Jaco A, Fuso A, Laviola G. Nicotine exposure during adolescence: cognitive performance and brain gene expression in adult heterozygous reeler mice. Psychopharmacology (Berl). 2014;231(8):1775-87. doi: 10.1007/s00213-013-3388-y.

140. Mostaid MS, Lloyd D, Liberg B, Sundram S, Pereira A, Pantelis C, et al. Neuregulin-1 and schizophrenia in the genome-wide association study era. Neurosci Biobehav Rev. 2016;68:387-409. doi: 10.1016/j.neubiorev.2016.06.001.

141. Mei L, Xiong WC. Neuregulin 1 in neural development, synaptic plasticity and schizophrenia. Nat Rev Neurosci. 2008;9(6):437-52. doi: 10.1038/nrn2392.

142. Jiang L, Emmetsberger J, Talmage DA, Role LW. Type III neuregulin 1 is required for multiple forms of excitatory synaptic plasticity of mouse cortico-amygdala circuits. J Neurosci. 2013;33(23):9655-66. doi: 10.1523/JNEUROSCI.2888-12.2013.

143. Chen YJ, Johnson MA, Lieberman MD, Goodchild RE, Schobel S, Lewandowski N, et al. Type III neuregulin-1 is required for normal sensorimotor gating, memoryrelated behaviors, and corticostriatal circuit components. J Neurosci. 2008;28(27):6872-83. doi: 10.1523/JNEUROSCI.1815-08.2008.

144. Suemaru K, Yasuda K, Umeda K, Araki H, Shibata K, Choshi $\mathrm{T}$, et al. Nicotine blocks apomorphine-induced disruption of prepulse inhibition of the acoustic startle in rats: possible involvement of central nicotinic alpha7 receptors. Br J Pharmacol. 2004;142(5):843-50. doi: 10.1038/sj.bjp.0705855.

145. Hancock ML, Canetta SE, Role LW, Talmage DA. Presy- naptic type III neuregulin1-ErbB signaling targets alpha7 nicotinic acetylcholine receptors to axons. J Cell Biol. 2008;181(3):511-21. doi: 10.1083/jcb.200710037.

146. Weickert CS, Tiwari Y, Schofield PR, Mowry BJ, Fullerton JM. Schizophrenia-associated HapICE haplotype is associated with increased NRG1 type III expression and high nucleotide diversity. Transl Psychiatry. 2012;2:e104. doi: 10.1038/tp.2012.25.

147. Olaya JC, Heusner CL, Matsumoto M, Shannon Weickert C, Karl T. Schizophrenia-relevant behaviours of female mice overexpressing neuregulin 1 type III. Behav Brain Res. 2018;353:227-235. doi: 10.1016/j.bbr.2018.03.026.

148. Olaya JC, Heusner CL, Matsumoto M, Sinclair D, Kondo MA, Karl T, et al. Overexpression of Neuregulin 1 Type III Confers Hippocampal mRNA Alterations and Schizophrenia-Like Behaviors in Mice. Schizophr Bull. 2017;doi: 10.1093/schbul/sbx122.

149. Calzavara MB, Levin R, Medrano WA, Almeida V, Sampaio AP, Barone LC, et al. Effects of antipsychotics and amphetamine on social behaviors in spontaneously hypertensive rats. Behav Brain Res. 2011;225(1):15-22. doi: 10.1016/j.bbr.2011.06.026.

150. Laprairie RB, Bagher AM, Kelly ME, Denovan-Wright EM. Cannabidiol is a negative allosteric modulator of the cannabinoid CB1 receptor. $\mathrm{Br} J$ Pharmacol. 2015;172(20):4790-805. doi: 10.1111/bph.13250.

151. Waldo Zuardi A, Crippa JA, Hallak JE, Bhattacharyya S, Atakan Z, Martin-Santos R, et al. A critical review of the antipsychotic effects of cannabidiol: 30 years of a translational investigation. Curr Pharm Des. 2012;18(32):513140. doi: $10.2174 / 138161212802884681$.

152. Almeida V, Levin R, Peres FF, Niigaki ST, Calzavara MB, Zuardi AW, et al. Cannabidiol exhibits anxiolytic but not antipsychotic property evaluated in the social interaction test. Prog Neuropsychopharmacol Biol Psychiatry. 2013;41:30-5. doi: 10.1016/j.pnpbp.2012.10.024.

153. Peres FF, Diana MC, Levin R, Suiama MA, Almeida V, Vendramini AM, et al. Cannabidiol Administered During Peri-Adolescence Prevents Behavioral Abnormalities in an Animal Model of Schizophrenia. Front Pharmacol. 2018;9:901. doi: 10.3389/fphar.2018.00901.

154. Mandolini GM, Lazzaretti M, Pigoni A, Oldani L, Delvecchio G, Brambilla P. Pharmacological properties of cannabidiol in the treatment of psychiatric disorders: a critical overview. Epidemiol Psychiatr Sci. 2018;27(4):327-335. doi: 10.1017/S2045796018000239.

155. Karl T, Burne THJ, Van den Buuse $M$, Chesworth R. Do transmembrane domain neuregulin 1 mutant mice exhibit a reliable sensorimotor gating deficit? Behavioural Brain Research. 2011;223:336-341. doi: 10.1016/j.bbr.2011.04.051.

156. Karl T, Duffy L, Scimone A, Harvey RP, Schofield PR. Altered motor activity, exploration and anxiety in heterozygous neuregulin 1 mutant mice: implications for understanding schizophrenia. Genes Brain Behav. 2007;6(7):677-87. doi: 10.1111/j.1601183X.2006.00298.x.

157. Long LE, Chesworth R, Huang XF, Wong A, Spiro A, McGregor IS, et al. Distinct neurobehavioural effects of cannabidiol in transmembrane domain neuregulin $1 \mathrm{mu}-$ tant mice. PLoS One. 2012;7(4):e34129. doi: 10.1371/journal.pone.0034129.

158. Segal-Gavish H, Gazit N, Barhum Y, Ben-Zur T, Taler $\mathrm{M}$, Hornfeld SH, et al. BDNF overexpression prevents cognitive deficit elicited by adolescent cannabis exposure and host susceptibility interaction. Hum Mol Genet. 2017;26(13):2462-2471. doi: 10.1093/hmg/ddx139.

159. Boucher AA, Arnold JC, Duffy L, Schofield PR, Micheau 
J, Karl T. Heterozygous neuregulin 1 mice are more sensitive to the behavioural effects of Delta9tetrahydrocannabinol. Psychopharmacology (Berl). 2007;192(3):325-36. doi: 10.1007/s00213-007-0721-3.

160. Long LE, Chesworth R, Arnold JC, Karl T. A followup study: acute behavioural effects of Delta(9)-THC in female heterozygous neuregulin 1 transmembrane domain mutant mice. Psychopharmacology (Berl). 2010;211(3):277-89. doi: 10.1007/s00213-010-1896-6.

161. Lloyd D, Talmage D, Shannon Weickert C, Karl T. Reduced type III neuregulin 1 expression does not modulate the behavioural sensitivity of mice to acute Delta(9)tetrahydrocannabinol (D(9)-THC). Pharmacol Biochem Behav. 2018;170:64-70. doi: 10.1016/j.pbb.2018.05.003.

162. Long LE, Chesworth R, Huang XF, McGregor IS, Arnold JC, Karl T. Transmembrane domain Nrg1 mutant mice show altered susceptibility to the neurobehavioural actions of repeated THC exposure in adolescence. Int J Neuropsychopharmacol. 2013;16(1):163-75. doi: 10.1017/S1461145711001854.

163. Spencer JR, Darbyshire KM, Boucher AA, Kashem MA, Long LE, McGregor IS, et al. Novel molecular changes induced by Nrg1 hypomorphism and Nrg1-cannabinoid interaction in adolescence: a hippocampal proteomic study in mice. Front Cell Neurosci. 2013;7:15. doi: 10.3389/fncel.2013.00015.

164. Burnet PW, Eastwood SL, Harrison PJ. 5-HT1A and 5HT2A receptor mRNAs and binding site densities are differentially altered in schizophrenia. Neuropsychopharmacology. 1996;15(5):442-55. doi: 10.1016/S0893133X(96)00053-X.

165. Kang K, Huang XF, Wang Q, Deng C. Decreased density of serotonin $2 \mathrm{~A}$ receptors in the superior temporal gyrus in schizophrenia-a postmortem study. Prog Neuropsychopharmacol Biol Psychiatry. 2009;33(5):867-71. doi: 10.1016/j.pnpbp.2009.04.010.

166. Compton MT, Kelley ME, Ramsay CE, Pringle M, Goulding SM, Esterberg ML, et al. Association of pre-onset cannabis, alcohol, and tobacco use with age at onset of prodrome and age at onset of psychosis in first-episode patients. Am J Psychiatry. 2009;166(11):1251-7. doi: 10.1176/appi.ajp.2009.09030311.

167. Decoster J, van Os J, Kenis G, Henquet C, Peuskens $J$, De Hert $M$, et al. Age at onset of psychotic disorder: cannabis, BDNF Val66Met, and sex-specific models of gene-environment interaction. Am J Med Genet B Neuropsychiatr Genet. 2011;156B(3):363-9. doi: 10.1002/ajmg.b.31174.

168. Donoghue K, Doody GA, Murray RM, Jones PB, Morgan C, Dazzan P, et al. Cannabis use, gender and age of onset of schizophrenia: data from the $\mathrm{AE}-$ SOP study. Psychiatry Res. 2014;215(3):528-32. doi: 10.1016/j.psychres.2013.12.038.

169. Koskinen J, Lohonen J, Koponen $\mathrm{H}$, Isohanni $\mathrm{M}, \mathrm{Mi}-$ ettunen J. Rate of cannabis use disorders in clinical samples of patients with schizophrenia: a metaanalysis. Schizophr Bull. 2010;36(6):1115-30. doi: 10.1093/schbul/sbp031.

170. Berg SA, Sentir AM, Bell RL, Engleman EA, Chambers RA. Nicotine effects in adolescence and adulthood on cognition and alpha(4)beta(2)-nicotinic receptors in the neonatal ventral hippocampal lesion rat model of schizophrenia. Psychopharmacology (Berl). 2015;232(10):1681-92. doi: 10.1007/s00213-014-3800-2.

171. Straley ME, Van Oeffelen W, Theze S, Sullivan AM, O'Mahony SM, Cryan JF, et al. Distinct alterations in motor \& reward seeking behavior are dependent on the gestational age of exposure to LPS-induced maternal im- mune activation. Brain Behav Immun. 2017;63:21-34. doi: 10.1016/j.bbi.2016.06.002.

172. Alkhattabi N, Todd I, Negm O, Tighe PJ, Fairclough LC. Tobacco smoke and nicotine suppress expression of activating signaling molecules in human dendritic cells. Toxicol Lett. 2018;299:40-46. doi: 10.1016/j.toxlet.2018.09.002.

173. Cui WY, Zhao S, Polanowska-Grabowska R, Wang J, Wei J, Dash B, et al. Identification and characterization of poly(I:C)-induced molecular responses attenuated by nicotine in mouse macrophages. Mol Pharmacol. 2013;83(1):61-72. doi: 10.1124/mol.112.081497.

174. Osborne AL, Solowij N, Babic I, Huang XF, Weston-Green K. Improved Social Interaction, Recognition and Working Memory with Cannabidiol Treatment in a Prenatal Infection (poly I:C) Rat Model. Neuropsychopharmacology. 2017;42(7):1447-1457. doi: 10.1038/npp.2017.40.

175. Osborne AL, Solowij N, Babic I, Lum JS, Newell KA, Huang XF, et al. Effect of cannabidiol on endocannabinoid, glutamatergic and GABAergic signalling markers in male offspring of a maternal immune activation (poly I:C) model relevant to schizophrenia. Prog Neuropsychopharmacol Biol Psychiatry. 2019;95:109666. doi: 10.1016/j.pnpbp.2019.109666.

176. Osborne AL, Solowij N, Babic I, Lum JS, Huang XF, Newell $\mathrm{KA}$, et al. Cannabidiol improves behavioural and neurochemical deficits in adult female offspring of the maternal immune activation (poly I:C) model of neurodevelopmental disorders. Brain Behav Immun. 2019;81:574-587. doi: 10.1016/j.bbi.2019.07.018.

177. Gomes FV, Guimaraes FS, Grace AA. Effects of pubertal cannabinoid administration on attentional set-shifting and dopaminergic hyper-responsivity in a developmental disruption model of schizophrenia. Int J Neuropsychopharmacol. 2014;18(2). doi: 10.1093/ijnp/pyu018.

178. D'Souza DC, Sewell RA, Ranganathan M. Cannabis and psychosis/schizophrenia: human studies. Eur Arch Psychiatry Clin Neurosci. 2009;259(7):413-31. doi: 10.1007/s00406-009-0024-2.

179. Aguilar DD, Giuffrida A, Lodge DJ. Adolescent Synthetic Cannabinoid Exposure Produces Enduring Changes in Dopamine Neuron Activity in a Rodent Model of Schizophrenia Susceptibility. Int J Neuropsychopharmacol. 2018;21(4):393-403. doi: 10.1093/ijnp/pyy003.

180. Caspi A, Moffitt TE, Cannon M, McClay J, Murray R, Harrington $\mathrm{H}$, et al. Moderation of the effect of adolescentonset cannabis use on adult psychosis by a functional polymorphism in the catechol-O-methyltransferase gene: longitudinal evidence of a gene $\mathrm{X}$ environment interaction. Biol Psychiatry. 2005;57(10):1117-27. doi: 10.1016/j.biopsych.2005.01.026.

181. Henquet C, Krabbendam L, Spauwen J, Kaplan C, Lieb R, Wittchen HU, et al. Prospective cohort study of cannabis use, predisposition for psychosis, and psychotic symptoms in young people. BMJ. 2005;330(7481):11. doi: $10.1136 / \mathrm{bmj} .38267 .664086 .63$.

182. French L, Gray C, Leonard G, Perron M, Pike GB, Richer L, et al. Early Cannabis Use, Polygenic Risk Score for Schizophrenia and Brain Maturation in Adolescence. JAMA Psychiatry. 2015;72(10):1002-11. doi: 10.1001/jamapsychiatry.2015.1131.

183. Bédard AM, Maheux J, Levesque D, Samaha AN. Continuous, but not intermittent, antipsychotic drug delivery intensifies the pursuit of reward cues. Neuropsychopharmacology. 2011;36(6):1248-59. doi: 10.1038/npp.2011.10.

184. Bédard AM, Maheux J, Levesque D, Samaha AN. Prior haloperidol, but not olanzapine, exposure augments the pursuit of reward cues: implications for substance abuse in schizophrenia. Schizophr Bull. 2013;39(3):692-702. 
doi: 10.1093/schbul/sbs077.

185. El Hage C, Bédard AM, Samaha AN. Antipsychotic treatment leading to dopamine supersensitivity persistently alters nucleus accumbens function. Neuropharmacology. 2015;99:715-25. doi: 10.1016/j.neuropharm.2015.03.012.

186. Light GA, Hsu JL, Hsieh MH, Meyer-Gomes K, Sprock J, Swerdlow NR, et al. Gamma band oscillations reveal neural network cortical coherence dysfunction in schizophrenia patients. Biol Psychiatry. 2006;60(11):1231-40. doi: 10.1016/j.biopsych.2006.03.055.

187. Sivarao DV, Frenkel M, Chen P, Healy FL, Lodge NJ, Zaczek R. MK-801 disrupts and nicotine augments $40 \mathrm{~Hz}$ auditory steady state responses in the auditory cortex of the urethane-anesthetized rat. Neuropharmacology. 2013;73:1-9. doi: 10.1016/j.neuropharm.2013.05.006.

188. Cadinu D, Grayson B, Podda G, Harte MK, Doostdar N, Neill JC. NMDA receptor antagonist rodent models for $\operatorname{cog}$ nition in schizophrenia and identification of novel drug treatments, an update. Neuropharmacology. 2018;142:4162. doi: 10.1016/j.neuropharm.2017.11.045.

189. Brown JW, Rueter LE, Zhang M. Predictive validity of a MK-801-induced cognitive impairment model in mice: implications on the potential limitations and challenges of modeling cognitive impairment associated with schizophrenia preclinically. Prog Neuropsychopharmacol Biol Psychiatry. 2014;49:53-62. doi: 10.1016/j.pnpbp.2013.11.008.

190. Scott D, Taylor JR. Chronic nicotine attenuates phencyclidine-induced impulsivity in a mouse serial reaction time task. Behav Brain Res. 2014;259:164-73. doi: 10.1016/j.bbr.2013.11.009.

191. Cloke JM, Nguyen R, Chung BY, Wasserman DI, De Lisio S, Kim JC, et al. A Novel Multisensory Integration Task Reveals Robust Deficits in Rodent Models of Schizophrenia: Converging Evidence for Remediation via Nicotinic Receptor Stimulation of Inhibitory Transmission in the Prefrontal Cortex. J Neurosci. 2016;36(50):12570-12585. doi: 10.1523/JNEUROSCI.1628-16.2016.

192. Rodríguez G, Neugebauer NM, Yao KL, Meltzer HY, Csernansky JG, Dong H. Delta9-tetrahydrocannabinol (Delta9-THC) administration after neonatal exposure to phencyclidine potentiates schizophrenia-related behavioral phenotypes in mice. Pharmacol Biochem Behav. 2017;159:6-11. doi: 10.1016/j.pbb.2017.06.010.

193. Aguilar DD, Giuffrida A, Lodge DJ. THC and endocannabinoids differentially regulate neuronal activity in the prefrontal cortex and hippocampus in the subchronic PCP model of schizophrenia. J Psychopharmacol. 2016;30(2):169-81. doi: 10.1177/0269881115612239.

194. Skosnik PD, Cortes-Briones JA, Hajós M. It's All in the Rhythm: The Role of Cannabinoids in Neural Oscillations and Psychosis. Biol Psychiatry. 2016;79(7):568-77. doi: 10.1016/j.biopsych.2015.12.011.

195. Spano MS, Fattore L, Cadeddu F, Fratta W, Fadda P. Chronic cannabinoid exposure reduces phencyclidineinduced schizophrenia-like positive symptoms in adult rats. Psychopharmacology (Berl). 2013;225(3):531-42. doi: 10.1007/s00213-012-2839-1.

196. Seillier A, Martinez AA, Giuffrida A. Phencyclidineinduced social withdrawal results from deficient stimulation of cannabinoid $\mathrm{CB}(1)$ receptors: implications for schizophrenia. Neuropsychopharmacology. 2013;38(9):1816-24. doi: 10.1038/npp.2013.81.

197. Matricon J, Seillier A, Giuffrida A. Distinct neuronal activation patterns are associated with PCP-induced social withdrawal and its reversal by the endocannabinoidenhancing drug URB597. Neurosci Res. 2016;110:49-58. doi: 10.1016/j.neures.2016.04.004.
198. Szúcs E, Dvorácskó S, Tömböly C, Büki A, Kékesi G, Horváth $\mathrm{G}$, et al. Decreased CB receptor binding and cannabinoid signaling in three brain regions of a rat model of schizophrenia. Neurosci Lett. 2016;633:87-93. doi: 10.1016/j.neulet.2016.09.020.

199. Eggan SM, Hashimoto T, Lewis DA. Reduced cortical cannabinoid 1 receptor messenger RNA and protein expression in schizophrenia. Arch Gen Psychiatry. 2008;65(7):772-84. doi: 10.1001/archpsyc.65.7.772.

200. Eggan SM, Stoyak SR, Verrico CD, Lewis DA. Cannabinoid $\mathrm{CB} 1$ receptor immunoreactivity in the prefrontal cortex: Comparison of schizophrenia and major depressive disorder. Neuropsychopharmacology. 2010;35(10):2060-71. doi: $10.1038 / \mathrm{npp} .2010 .75$.

201. Fernandez-Espejo E, Viveros MP, Nunez L, Ellenbroek BA, Rodriguez de Fonseca F. Role of cannabis and endocannabinoids in the genesis of schizophrenia. Psychopharmacology (Berl). 2009;206(4):531-49. doi: 10.1007/s00213-009-1612-6.

202. Müller-Vahl KR, Emrich HM. Cannabis and schizophrenia: towards a cannabinoid hypothesis of schizophrenia. Expert Rev Neurother. 2008;8(7):1037-48. doi: 10.1586/14737175.8.7.1037.

203. Moran LV, Stoeckel LE, Wang K, Caine CE, Villafuerte $\mathrm{R}$, Calderon $\mathrm{V}$, et al. Nicotine-induced activation of caudate and anterior cingulate cortex in response to errors in schizophrenia. Psychopharmacology (Berl). 2018;235(3):789-802. doi: 10.1007/s00213-017-4794-3.

204. Smucny J, Tregellas JR. Targeting neuronal dysfunction in schizophrenia with nicotine: Evidence from neurophysiology to neuroimaging. J Psychopharmacol. 2017;31(7):801-811. doi: 10.1177/0269881117705071.

205. Manrique-Garcia E, Zammit S, Dalman C, Hemmingsson T, Andreasson S, Allebeck P. Prognosis of schizophrenia in persons with and without a history of cannabis use. Psychol Med. 2014;44(12):2513-21. doi: 10.1017/So033291714000191.

206. Leweke FM, Piomelli D, Pahlisch F, Muhl D, Gerth CW, Hoyer C, et al. Cannabidiol enhances anandamide signaling and alleviates psychotic symptoms of schizophrenia. Transl Psychiatry. 2012;2:e94. doi: 10.1038/tp.2012.15.

207. Swerdlow NR, Bhakta SG, Talledo JA, Franz DM, Hughes EL, Rana BK, et al. Effects of Amphetamine on Sensorimotor Gating and Neurocognition in AntipsychoticMedicated Schizophrenia Patients. Neuropsychopharmacology. 2018;43(4):708-717. doi: 10.1038/npp.2017.285.

208. Ibarra-Lecue I, Pilar-Cuéllar F, Muguruza C, FlorensaZanuy E, Diaz A, Urigüen L, et al. The endocannabinoid system in mental disorders: Evidence from human brain studies. Biochem Pharmacol. 2018;157:97-107. doi: 10.1016/j.bcp.2018.07.009.

209. Poels EM, Kegeles LS, Kantrowitz JT, Slifstein M, Javitt DC, Lieberman JA, et al. Imaging glutamate in schizophrenia: review of findings and implications for drug discovery. Mol Psychiatry. 2014;19(1):20-9. doi: 10.1038/mp.2013.136.

210. de Jonge JC, Vinkers $\mathrm{CH}$, Hulshoff Pol HE, Marsman A. GABAergic Mechanisms in Schizophrenia: Linking Postmortem and In Vivo Studies. Front Psychiatry. 2017;8:118. doi: 10.3389/fpsyt.2017.00118.

211. Selvaraj S, Arnone D, Cappai A, Howes O. Alterations in the serotonin system in schizophrenia: a systematic review and meta-analysis of postmortem and molecular imaging studies. Neurosci Biobehav Rev. 2014;45:233-45. doi: 10.1016/j.neubiorev.2014.06.005.

212. Sara GE, Burgess PM, Malhi GS, Whiteford HA, Hall WC. Stimulant and other substance use disorders in schizophrenia: prevalence, correlates and impacts 
in a population sample. Aust N Z J Psychiatry. 2014;48(11):1036-47. doi: 10.1177/0004867414533838.

213. Barnett $\mathrm{JH}$, Werners $\mathrm{U}$, Secher SM, Hill KE, Brazil $\mathrm{R}$, Masson K, et al. Substance use in a populationbased clinic sample of people with first-episode psychosis. Br J Psychiatry. 2007;190:515-20. doi: 10.1192/bjp.bp.106.024448.

\section{Copyright and License}

Copyright (C) 2020.The Author(s). Except where otherwise noted, the content of this article is licensed under a Creative Commons Attribution 4.0 International License. You are free to reuse or adapt this article for any purpose, provided appropriate acknowledgement is provided. For additional permissions, please contact the corresponding author. 